Revista peruana de biología 26(4): 443 - 460 (2019) doi: http://dx.doi.org/10.15381/rpb.v26i4.17215 ISSN-L 1561-0837; eISSN: 1727-9933

Universidad Nacional Mayor de San Marcos

\section{The genus Cyriocosmus Simon 1903 and two new species from Peru (Araneae: Theraphosidae: Theraphosinae)}

\section{TRABAJOS ORIGINALES}

$\begin{array}{ll}\text { Presentado: } & 19 / 04 / 2019 \\ \text { Aceptado: } & 20 / 10 / 2019 \\ \text { Publicado online: } & 16 / 12 / 2019\end{array}$

\section{Correspondencia:}

radan.kaderka@seznam.cz

Faculty of Forestry and Wood Technology, Mendel University, Zemědělská 1665/1, 61300 Brno, Czechia

Otros datos de los autores / biografía: https://orcid.org/0000-0003-3624-2143

Citación:

Kaderka R. 2019. The genus Cyriocosmus Simon 1903 and two new species from Peru (Araneae: Theraphosidae: Theraphosinae). Revista peruana de biología 26(4): 443 - 460 (Diciembre 2019). doi: http://dx.doi.org/10.15381/rpb.v26i4.17215

Palabras clave: Mygalomorphae; América de Sur; taxonomía; biodiversidad; Amazonas; bosques; diversidad de especies; Arañas.

Keywords: Mygalomorphae; South America; taxonomy; biodiversity; Amazon; Forests; Species diversity; Spiders.

\section{El género Cyriocosmus Simon 1903 y dos espécies nuevas de Peru (Araneae: Theraphosidae: Theraphosinae)}

\section{Radan Kaderka}

Mendel University, Faculty of Forestry and Wood Technology, Brno, Czech Republic.

\begin{abstract}
A female of Cyriocosmus giganteus Kaderka 2016 is described and illustrated for the first time, a new diagnosis of this species is proposed. Cyriocosmus paredesi sp. nov. from Quebrada Putuiman (Marañon River) and Cyriocosmus foliatus sp. nov. from Umaral near Iquitos, both from Loreto Department in Peru, are described, diagnosed, illustrated and keyed. The male of Cyriocosmus sellatus (Simon 1889) from Rio Blanco, the tributary of Rio Tahuyao, Loreto Department in Peru, is redescribed and figured. The distribution area of this species is updated, and difficulties in the identification of this species are discussed.

\section{Resumen}

Se describe e ilustra por la primera vez la hembra de Cyriocosmus giganteus Kaderka 2016, la diagnosis de esta especie es nuevamente propuesta. Se describe, diagnostica e ilustra a Cyriocosmus paredesi sp. nov. de la Quebrada Putuiman (Río Marañón) y Cyriocosmus foliatus sp. nov. de Umaral cerca de Iquitos, ambos del Departamento de Loreto en Perú. Se presenta una clave para las especies. Se redescribe e ilustra el macho de Cyriocosmus sellatus (Simon 1889) de Río Blanco, el afluente del Río Tahuyao, Departamento de Loreto en Perú. Se presenta el área actualizada de distribución de esta especie y se discuten dificultades para su identificación.
\end{abstract}

Publicación registrada en Zoobank/ZooBank article registered:

LSIDurn:|sid:zoobank.org:pub:41210952-7568-4281-BED6-2854218BA428

Acto nomenclatural/nomenclatural act:

Cyriocosmus paredesi Kaderka, 2019

LSIDurn:Isid:zoobank.org:act:D579F0C9-BF24-435B-B7F5-8981A70EFD50

Cyriocosmus paredesi Kaderka, 2019

LSIDurn:Isid:zoobank.org:act:D579F0C9-BF24-435B-B7F5-8981A70EFD50 


\section{Introduction}

In 1889, Simon described Hapalopus sellatus Simon 1889 from the Upper Amazon and Hapalopus elegans Simon 1889 from Venezuela. In 1897, Simon described Cyclosternum versicolor Simon 1897 from Paraguay. In 1903, Simon established Cyriocosmus Simon 1903 to accommodate both species primarily described in Hapalopus Ausserer 1875, with Cyriocosmus sellatus as the generic type. Later on, Mello-Leitão (1930) established Pseudhomoeomma Mello-Leitão 1930, with Pseudhomoeomma fasciatum Mello-Leitão 1930 from Pará, Brazil as the generic type. Mello-Leitão (1939) described the male of Cyriocosmus semifasciatus Mello-Leitão 1939 from Trinidad and the female of Cyriocosmus nigriventris Mello-Leitão 1939 from Venezuela. Roewer (1942) transferred Cyclosternum versicolor to the genus Hapalopus. Later on, in 1973, Schiapelli \& Gerschman newly defined the genus Cyriocosmus, synonymized Pseudhomoeomma with Cyriocosmus and Pseudhomoeomma fasciatum and Cyriocosmus semifasciatus with Cyriocosmus elegans and transferred Hapalopus versicolor (Simon 1897) to Cyriocosmus. Raven (1985) synonymized Erythropoicila Fischel 1927 from Venezuela with Cyriocosmus, with which it shares the divided tarsal scopulae and the characteristic elongate paraembolic apophysis, as well as Erythropoicila plana Fischel 1927 with Cyriocosmus elegans (Raven 1985). In 1998, Pérez-Miles described five new species (Cyriocosmus butantan Pérez-Miles 1998, C. chicoi Pérez-Miles 1998, C. ritae Pérez-Miles 1998, C. bertae Pérez-Miles 1998 from Brazil and C. blenginii Pérez-Miles 1998 from Bolivia), transferred Cyriocosmus nigriventris from Venezuela to Metriopelma Becker 1878, and carried out a phylogenetic analysis of the genus Cyriocosmus. Vol (1999) described Cyriocosmus leetzi Vol 1999 from Colombia. Fukushima et al. (2005) described two new species, Cyriocosmus fernandoi Fukushima et al. 2005 and Cyriocosmus nogueiranetoi Fukushima et al. 2005, restored Cyriocosmus fasciatus (contra Schiapelli \& Gerschman 1973), transferred Cyriocosmus butantan and Metriopelma nigriventris to Hapalopus and performed a new cladistic analysis of Cyriocosmus. In 2009, Pérez-Miles \& Weinmann described two new species, Cyriocosmus pribiki Pérez-Miles \& Weinmann 2009 and Cyriocosmus rogerioi Pérez-Miles \& Weinmann 2009, from Peru. In 2007 and 2010, Kaderka described Cyriocosmus perezmilesi Kaderka 2007 from the Beni province in Bolivia and C. venezuelensis Kaderka 2010 from Venezuela and synonymized Cyriocosmus rogerioi with C. pribiki. In 2016, he added seven new species, namely Cyriocosmus peruvianus Kaderka 2016, C. itayensis Kaderka 2016, C. aueri Kaderka 2016 and C. giganteus Kaderka 2016 from Peru, C. hoeferi Kaderka 2016 from Brazil and C. williamlamari Kaderka 2016 and C. nicholausgordoni Kaderka 2016 from Venezuela. In 2017, Gabriel synonymized C. chicoi Pérez-Miles 1998 with C. bicolor (Schiapelli \& Gerschman 1945).

Cyriocosmus giganteus was described according to a single male from Rio Blanco, the tributary of Rio Tahuyao, Loreto Department in Peru. The morphology of palpal bulb was unusual because of the absence of prolater- al superior keel. In October 2017, during the filed work in the locality of the type specimen near the Estacion Biológica Quebrada Blanco, a few females of $C$. giganteus were found and after their examination it was confirmed that this species really belongs to the genus Cyriocosmus as it was proposed by Kaderka (2016), mainly because of the spermatheca consisting of two separated spiral seminal receptacles with convex basal plates, and terminating with a globular extension. The female of Cyriocosmus giganteus is, herein, described and illustrated for the first time, a new diagnosis of this species is proposed. In October 2017, from the examination of material deposited at the Museo de Historia Natural in Lima, Peru, two new Cyriocosmus species from Loreto Department were discovered and are, herein, described, diagnosed, illustrated and keyed: Cyriocosmus paredesi sp. nov. from Quebrada Putuiman (Marañon River) and Cyriocosmus foliatus sp. nov. from Umaral near Iquitos. The male of Cyriocosmus sellatus (Simon 1889) from Rio Blanco, the tributary of Rio Tahuyao, Loreto Department in Peru, is redescribed and figured. The distribution area of this species is updated, and difficulties in the identification of this species are discussed.

\section{Material and methods}

The material for this study was obtained from different institutions and private collections. The types were separately preserved in $70 \%$ ethanol and stored in the depository of Museo de Historia Natural of Universidad Nacional Mayor de San Marcos (MUSM). All material was examined and measured using a binocular microscope Leica S6D with the magnification range from $6.3 \mathrm{x}$ up to 40x and an ocular micrometer $10 \mathrm{~mm} / 0.1 \mathrm{~mm}$. All measurements were taken according to the central axis of structures and are provided in millimetres. The measurements of the leg and palpal segments were taken dorsally. The eye measurements were taken from the widest spans of the lens, anterior median eyes in dorsal view, anterior lateral eyes, posterior lateral eyes and posterior median eyes in dorsolateral view. The measurement of the total body length, excluding chelicerae and spinnerets, was made using a calliper.

The extents of tarsal and metatarsal scopulae on the ventral side of both leg segments were expressed as a percentage of the total length of the segment.

Leg spination was described using the following method: each leg segment was divided into four quadrants (dorsal, ventral, prolateral and retrolateral) and each quadrant separately described, e.g. metatarsus I v 1-0-3 means that in the ventral plane (quadrant) there is one spine in basal section and three spines in apical section. If the bases of all three spine in apical section are located apically, then their position would be described by the term "apical" in brackets as in Bertani (2001). Unequal numbers of spines on the right and left side of the same leg segment were expressed by parentheses.

Denticulation of paired tarsal claws is described separately for prolateral and retrolateral claw (prolateral/ retrolateral). 
Female spermathecae and male palpal bulbs were separated from the body and preserved in microvials in $70 \%$ alcohol together with the specimen. The terminology of male palpal bulb structures follows Bertani (2000). The terminology of spermathecal morphology follows Fukushima et al. (2005). The sclerotized basal plates of seminal receptacles, if present, can be flat, slightly convex or convex from dorsal view. The convex basal plates are mostly concave in ventral view.

Abdominal urticating setae were removed from the area of urticating setae by tweezers, placed in alcohol and examined using a binocular microscope Olympus BH2-RFCA with magnification up to $40 \mathrm{x}$. The terminology of urticating setae follows Cooke et al. (1972). The barbs of urticating setae whose tips are oriented towards the body are considered as reversed.

Photographs of preserved material were taken with a Canon G5 mounted directly on the eye piece of a binocular microscope Leica S6D illuminated by an incorporated LED ringlight. Photographs of live specimens were taken with a Canon G5. Line drawings were drawn according to the photos, using a transparent foil. Maps were made with SimpleMappr, an online tool to produce species distribution maps (Shorthouse 2010).

Abbreviations: Eye sizes and interdistances: $\mathrm{AME}=$ anterior median eyes, ALE = anterior lateral eyes, PME = posterior median eyes, $\mathrm{PLE}=$ posterior lateral eyes, $\mathrm{OQ}$ = ocular quadrangle (including lateral eyes). Spination: $p$ = prolateral, $\mathrm{r}=$ retrolateral, $\mathrm{d}=$ dorsal, $\mathrm{v}=$ ventral. Male palpal bulb: $\mathrm{PA}=$ paraembolic apophysis, $\mathrm{PS}=$ prolateral superior keel, $\mathrm{A}=$ apical keel, $\mathrm{E}=$ embolus, $\mathrm{TP}=$ tegular protuberance. Cheliceral teeth pattern: $\mathrm{v}=$ small teeth, $\mathrm{V}$ = big teeth, - = space. PLS = posterior lateral spinnerets, PMS = posterior median spinnerets. Collections: MNHN = Muséum National d'Histoire Naturelle, Paris. MUSM = Museo de Historia Natural, Lima, Peru. NMPC = National Museum (Natural History), Praha, Czech Republic. RKCP = Radan Kaderka private collection, Czech Republic. SMFD = Senckenberg Museum, Frankfurt, Germany. SMNK = Staatliches Museum für Naturkunde, Karlsruhe, Germany.

Other material examined: Cyriocosmus aueri Kaderka 2016, male holotype (NMPC P6A-5729), female paratype (NMPC P6A-5730), female paratype (SMFD) from Peru, Iquitos, the Amazon River, Nuevo Umaral, May 2009, Hans-Werner Auer col.; Cyriocosmus aueri Kaderka 2016, male paratype (SMFD) from Peru, Loreto, Rio Tigre, Comunidad Monteverde, 04¹4'42.95”S, 74²1'36.02”W, April 2, 1993, Dr. William Lamar col.; Cyriocosmus aueri Kaderka 2016, male paratype (MUSM-ENT 0504033) from Peru, Loreto, Rio Tigre, Cocha Shinguito, $05^{\circ} 08^{\prime} \mathrm{S}$, $74^{\circ} 45^{\prime}$ W, ca. 100 m a.s.l., May 25, 1990, Diana Silva Dávila col.; Cyriocosmus elegans (Simon 1889), female (SMFD) from West Indies, Trinidad Island, Icacos Point, May 17, 1989, T. Mason col.; Cyriocosmus giganteus Kaderka 2016, male holotype (MUSM-ENT 0505244) from Peru, Loreto, Rio Blanco, tributary of Rio Tahuyao, Estación Biologica Quebrada Blanco, 4²1'S, 7309'W, September 11, 2007, Peter Gottleuber col.; Cyriocosmus giganteus Kaderka
2016, male (MUSM-ENT 0511866), female (MUSM-ENT 0511862) and female (MUSM-ENT 0511867) from Peru, Loreto, Rio Blanco, tributary of Rio Tahuyao, Estación Biologica Quebrada Blanco, October 12-15, 2017, R. Kaderka col.; Cyriocosmus hoeferi Kaderka 2016, male holotype (INPA 8803, formely SMNK-ARA 0956) from Brazil, Manaus, Reserva Florestal Adolpho Ducke, 2 ${ }^{\circ} 55^{\prime} 40^{\prime \prime}$, 5958'10"W, March 18, 1992, Hubert Höfer and Thierry Gasnier col.; Cyriocosmus hoeferi Kaderka 2016, female paratype (SMFD), male paratype (SMFD) from Brazil, Manaus, Rio Tarumã, $2 \mathrm{~km}$ from the confluence with Rio Negro, 301'10.4"'S, 6006'33.6”'W, June 1995, N. C. Gordon and R. C. West col.; Cyriocosmus itayensis Kaderka 2016, male holotype (NMPC P6A-5727), female paratype (NMPC P6A-5728), female (MUSM-ENT 0511870, formerly RKCP 0239), female (MUSM-ENT 0511869, formerly RKCP 0370) from Peru, Iquitos, Nauta, Rio Itaya, village of Luz del Oriente, March 2007, Hans-Werner Auer col., immature female (MUSM-ENT 0505128) from Peru, Loreto, Rio Itaya, July 18, 2012, Maria \& Diana Silva col.; Cyriocosmus leetzi Vol 1999, male holotype (MNHN AR 10111), female lectotype (MNHN AR 10112) from Colombia, without further information; Cyriocosmus leetzi Vol 1999, female (MUSM-ENT 0511871, formerly RKCP 0197) from Venezuela, State of Táchira, San Cristobal, Agua Dulce (440 m a.s.l.), March 2006, V. Fura \& B. Velas col.; Cyriocosmus nicholausgordoni Kaderka 2016, male holotype (SMFD), female paratype (SMFD) from Venezuela, State of Amazonas, Puerto Ayacucho, Pozo Crystal, February 15, 1995, Rick C. West col.; Cyriocosmus perezmilesi Kaderka 2007, male holotype (NMPC P6E-2983), female paratype (NMPC P6E-2985), male (MUSM-ENT 0511865, formerly RKCP 0174) from Bolivia, San Buenaventura, Beni province, October 14, 2004, Radan Kaderka col. (offspring of male holotype and female paratype); Cyriocosmus peruvianus Kaderka 2016, male holotype (NMPC P6A-5725), female paratype (NMPC P6A-5726), male (MUSM-ENT 0511866, formerly RKCP 0064), female (MUSM-ENT 0511867, formerly RKCP 0237), male (MUSM-ENT 0511868, formerly RKCP 0238) from Peru, Iquitos, Rio Nanay, village of Cuyana, 2008, Hans-Werner Auer col.; Cyriocosmus pribiki Pérez-Miles \& Weinmann 2009, male holotype (SMFD 60237), two female paratypes (SMFD 60238) from Peru, Amazonas, Tingo, Gualap, male (SMFD 60239, holotype of Cyriocosmus rogerioi Pérez-Miles \& Weinmann 2009) from Peru, Amazonas, Gualap, Chachapoyas, October 22, 1996, František Pribik col.; Cyriocosmus ritae Pérez-Miles 1998, male (NMPC P6A-5731, formerly RKCP 0347),-male (MUSMENT 0506544, formerly RKCP 0557), male (MUSM-ENT 0506545, formerly RKCP 0561), female (NMPC P6A5732, formerly RKCP 0348),-female (NMPC P6A-5732, formerly RKCP 0225), female (MUSM-ENT 0511864, formerly RKCP 0349), female (MUSM-ENT 0506543, formerly RKCP 0562), female (MUSM-ENT 0506546, formerly RKCP 0523) from Peru, Iquitos, the Amazon River, Las Palmas (approximately $60 \mathrm{~km}$ east from Iquitos), May 2009, Hans-Werner Auer col.; Cyriocosmus sellatus (Simon 1889), male allotype (MNHN AR 12331, formerly MNHN 8102) from the Upper Amazon River, São Paulo de Olivença, Fonte Boa, collector and date of collec- 
tion unknown; Cyriocosmus sellatus (Simon 1889), male (MUSM-ENT 0504034) from Peru, Loreto, Yanamono, 80 $\mathrm{km}$ east from Iquitos, 20-26 July, 1984, Rina Ramirez Mesias col.; Cyriocosmus sellatus (Simon 1889), male (MUSMENT 0511179) from Peru, Loreto, Estación Biologica Quebrada Blanco, $100 \mathrm{~km}$ south from Iquitos, $04^{\circ} 21^{\prime} \mathrm{S}$, 7309'W, 120 m a.s.l., 26 September, 2007, Peter Gottleuber col.; Cyriocosmus sellatus (Simon 1889), male (MUSMENT 0511861, formerly RKCP 0594) from Peru, Loreto, Reserva Nacional Allpahuayo - Mishana, 10 km from Iquitos, H.-W. Auer ded., May 2014; Cyriocosmus sp. 1, male (MUSM-ENT 0511863, formerly RKCP 0912) from Peru, Loreto, Indiana near Iquitos, $03^{\circ} 29.821^{\prime} \mathrm{S}, 7^{\circ} 02.991^{\prime} \mathrm{W}$, 87 m a.s.l., November 2014, Lorenzo Micheli col.; Cyriocosmus sp. 3 (cf. pribiki), female (MUSM-ENT 0504630, car. 5.8) from Peru, Amazonas, $4 \mathrm{~km}$ from Chachapoyas, road to Molinopampa, 06²13'24.9”S, 7750'04.7”W, 2.064 $\mathrm{m}$ a.s.l., August 16, 2008, W. Paredes col.; Cyriocosmus sp. 4, female (MUSM-ENT 0511872) from Peru, Loreto, Umaral near Iquitos, $03^{\circ} 42.076^{\prime} \mathrm{S}, 7^{\circ} 05.890^{\prime} \mathrm{W}, 101 \mathrm{~m}$ a.s.l., Nolberto Ahuanari col., October 20, 2017; Cyriocosmus sp. 5, female (MUSM-ENT 0506719) from Peru, Madre de Dios, $15 \mathrm{~km}$ East from Puerto Maldonado, $12^{\circ} 33^{\prime} \mathrm{S}$, 6903'W, June 27, 1989, Diana Silva Dávila col.; Cyriocosmus sp. 6, female (MUSM-ENT 0511862, formerly RKCP 0906) from Peru, Loreto, Nuevo Milagro near Iquitos, 0356.025'S, 73¹9.955'W, October 2016, Lorenzo Micheli col.; Cyriocosmus venezuelensis Kaderka 2010, male holotype (NMPC P6E-2997), female paratype (NMPC P6E2999) from Venezuela, State of Lara, Carora, $9^{\circ} 54^{\prime} 58^{\prime \prime} \mathrm{N}$, $70^{\circ} 15^{\prime} 13^{\prime \prime} \mathrm{W}$ (dry forest), February 2006, V. Fura and B. Velas col.; Cyriocosmus versicolor (Simon 1897), female (MNHN AR 4574) from Paraguay, Colonia Risso, without further information; Cyriocosmus williamlamari Kaderka 2016, female holotype (SMFD) from Venezuela, Apure, Rio Matiyure, Hato El Cedral, 7²8'36.12”N, 69²0'43.08”W, September 4, 1994, William Lamar col.

\section{Taxonomy \\ INFRAORDER MYGALOMORPHAE POCOCK 1892 \\ FAMILY THERAPHOSIDAE THORELL 1869 \\ SUBFAMILY THERAPHOSINAE THORELL 1869}

\section{Genus Cyriocosmus Simon 1903}

SYNONYMIES: Erythropoicila Fischel 1927; Pseudhomoeomma Mello-Leitão 1930

\section{TYPE SPECIES: Cyriocosmus sellatus (Simon 1889)}

Generic diagnosis: The genus Cyriocosmus differs from all known Theraphosinae genera by the presence of the paraembolic apophysis in male palpal bulbs (Figures $8,9,11,15$; Kaderka 2016: figure 32) and by the presence of spermathecae with two separated spiral seminal receptacles, mostly terminating with caliciform or globular extension (Figure 16, 17; Kaderka 2016: figure 29), with reversion in C. nogueiranetoi having S-shaped receptacles, in combination with the presence of the type III urticating setae (Kaderka 2010: figure 13) in the central patch on dorsal abdomen (Figures 1, 2, 3E, 5, 6D, 10F, 12, 13D).
Species included: $C$. aueri Kaderka 2016, C. bertae Pérez-Miles 1998, C. bicolor (Schiapelli \& Gerschman 1945), C. blenginii Pérez-Miles 1998, C. elegans (Simon 1889), C. fasciatus (Mello-Leitão 1930), C. fernandoi Fukushima, Bertani \& da Silva 2005, C. giganteus Kaderka 2016, C. hoeferi Kaderka 2016, C. itayensis Kaderka 2016, C. leetzi Vol 1999, C. nicholausgordoni Kaderka 2016, C. nogueiranetoi Fukushima, Bertani \& da Silva 2005, C. perezmilesi Kaderka 2007, C. peruvianus Kaderka 2016, C. pribiki Pérez-Miles \& Weinmann 2009, C. ritae PérezMiles 1998, C. sellatus (Simon 1889), C. venezuelensis Kaderka 2010, C. versicolor (Simon 1897), C. williamlamari Kaderka 2016.

Distribution: The genus Cyriocosmus is exclusive to (sub-)tropical South America (Schiapelli \& Gerschman de Pikelin 1973) including northern Argentina, Bolivia, Brazil, Colombia, Paraguay, Peru, Tobago, Trinidad and Venezuela, including Isla Margarita (Figure 18). Spiders of the genus inhabit tropical and non-tropical areas, lowland rainforests as well as high-altitude forests at the elevation of $3000 \mathrm{~m}$ a.s.l. (Fukushima et al. 2005; PérezMiles \& Weinmann 2009).

Re-description: The genus Cyriocosmus comprises small to medium-sized spiders, with total length 10-32 $\mathrm{mm}$, excluding chelicerae and spinnerets. Carapace oval, uniformly coloured or with bicoloured pattern. Caput moderately domed. Eye tubercle oval, flattened, distinctly wider than longer, with eight eyes, anterior eye row slightly procurved, posterior row slightly recurved in dorsal view, a group of strong setae present on the median anterior margin of the tubercle. Clypeus absent to very narrow. Fovea transverse, straight to slightly procurved. Chelicerae without rastellum and stridulatory bristles, with teeth on promargin (7-12), first basal teeth are complemented with granulation. Labium domed, wider than longer, with 30-100 cuspules in anterior third, maxillae with 100360 cuspules in basal half on ventral side, maxillary lobe pronounced into conical process. Variability in number of labial and maxillary cuspules in Cyriocosmus perezmilesi was described by Kaderka (2010). Labiosternal groove distinct, shallow and flat, with two slightly separate or joined elongated sigilla. Sternum oval, with three pairs of small, oval sigilla located near coxae III, coxae II and coxae I, posteriorly separated from the margin approximately by their own diameter. Legs uniformly hirsute, with (Figure 5; Kaderka 2016: figures 12, 15, 17, 34) or without (Figures 1, 2, 12; Kaderka 2016: figures 1, 4, 7) whitish or yellowish longitudinal striation on dorsal side. Leg pattern (from longest to shortest): I $>$ IV $>$ II $>$ III in Cyriocosmus ritae or IV $>$ I $>$ II $>$ III in all congeners. Leg segments: generally uniform to slightly incrassate on femur III. Incrassate tibia I is present in males of $C$. ritae only (Kaderka 2016: figure $24 b$ ).

Dense scopulae on ventral side of all tarsi, metatarsi partly scopulate, scopulae more extended on anterior than on posterior legs. Tarsal scopulae I, II usually undivided, on tarsi III, IV usually divided by a longitudinal band of setae. Retrolateral side of femur IV and prolateral side of femur I without pad of plumose setae. Maxillary 
and trochanteral stridulatory setae or bristles absent. Spination as in species descriptions. Dorsal side of all tarsi with two irregular longitudinal rows of very short claviform trichobothria. Paired tarsal claws with or without teeth, third claw absent in all tarsi. Claw tufts dense, bilobate, present on all tarsi.

Abdomen uniformly coloured (Figures 1, 2, 5, 10F, 13D) or with lateral stripes (Kaderka 2016: figures $12,16 c, 17,22,34)$. Urticating setae of type III (Kaderka 2010: figure 13) with very short reversed barbs are located in central oval (Figures 6D, 10F) to U-shaped glossy patch (Kaderka 2016: figures 1, 4, 17, 34). Abdomen ventrally with (Kaderka 2016: figures 16e, 23d) or without dark longitudinal band. Four spinnerets present. PLS composed of three digitiform segments. PMS digitiform, mono-segmented.

Male palpal organ: embolus with long (Figures 8C-H, 9A-B) or short PA (Figures 11,15) and with smooth (Figure 11) or crested PS keel (Fukushima et al. 2005: figures 1-4), PS keel is absent only in males of Cyriocosmus giganteus (Kaderka 2016: figures 25g-h). Apical keel is present only in Cyriocosmus versicolor, C. perezmilesi (Kaderka 2016: figures 32g-h; Fukushima et al. 2005: figures 1-2) and $C$. foliatus sp. nov. (Figure 15). Tegulum with distinct granulated TP, projecting prolaterally (Figures 8A, 8E, 9A, 11C, 15A-B). Retrolateral face of cymbium with (Kaderka 2016: figure 24a) or without basal field of spiniform setae (in Fukushima et al. 2005 called "spines"). Palpal tibia with distinct (Kaderka 2016: figures $2 \mathrm{e}, 5 \mathrm{e}, 21 \mathrm{f}, 24 \mathrm{a}$ ) or indistinct (Kaderka 2016: figures $10 \mathrm{e}, 13 \mathrm{~g}, 20 \mathrm{f})$ retrolateral process which is usually covered with numerous spiniform setae, absent in males of C. fernandoi, C. hoeferi, C. nogueiranetoi and C. versicolor. Two unequal tibial apophyses are present on tibia I (Kaderka 2016: figures 27-28): a longer retrolateral tibial apophysis, usually with short apical spine and a shorter prolateral tibial apophysis usually with single, well-developed retrolateral spine at base. Metatarsus I not sigmoidly curved, without basal or median protuberance on retrolateral face, except for males of $C$. ritae having a

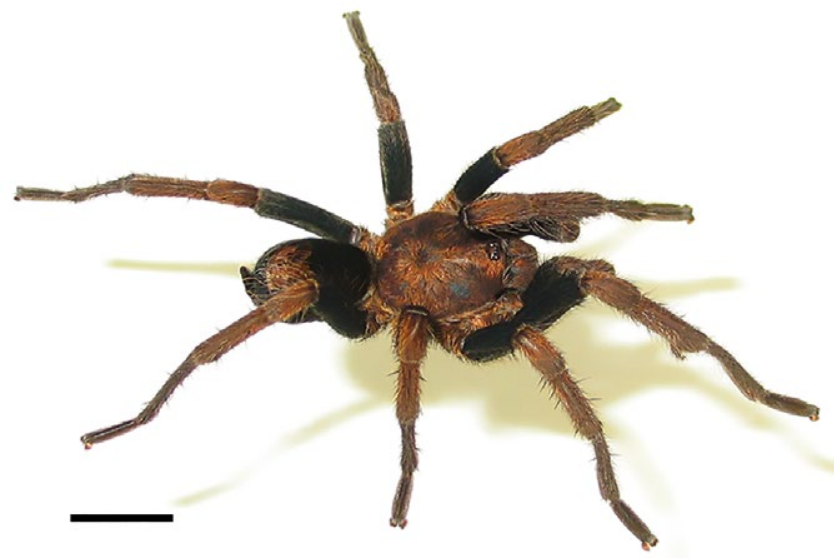

Figure 1. Cyriocosmus giganteus Kaderka 2016, male (MUSM-ENT 0511866) from Peru, Loreto, EBQB. Scale bar $=10 \mathrm{~mm}$. (photo by R. Kaderka) median protuberance (Kaderka 2016: figure 24b). Male metatarsus I flexion between both tibial apophyses, except for $C$. fernandoi and $C$. versicolor with flexion on retrolateral side of retrolateral tibial apophysis, $C$. pribiki with flexion on retrolateral tibial apophysis and $C$. ritae with flexion on prolateral tibial apophysis.

Females with spermathecae composed of two separated spiral seminal receptacles, distally terminating with caliciform (Figures 16A, 16D, 16F) or globular extension (Figures 16B-C, 16E, 16G-H), with or without sclerotized basal plates. If present they can be flat (Kaderka 2016: figures 29a, 29f) or convex (Kaderka 2016: figures 29c, 29g, 35a-b).

\section{Cyriocosmus giganteus Kaderka 2016}

$$
\text { (Figures 1-4, 16G, 17, 18, 19, Table 1) }
$$

Cyriocosmus giganteus: Kaderka 2016: 41-44, figures 20, 25g, 25h, 28b.

Types: Male holotype (MUSM-ENT 0505244) from Peru, Loreto, Estación Biológica Quebrada Blanco (EBQB), $4^{\circ} 21^{\prime} \mathrm{S}, 7^{\circ} 09^{\prime} \mathrm{W}$, September 11, 2007, Peter Gottleuber col.

Diagnosis: Cyriocosmus giganteus sp. nov. can be distinguished from all other congeners by the uniformly coloured carapace, abdomen without stripes and bicoloured legs with black femora, the rest leg segments are brown. Males distinguish by the palpal bulb without prolateral superior keel. Female spermathecae are composed of two separated spiral seminal receptacles, distally terminating with globular extension.

Distribution (Figures 18, 19): Known only from the type locality.

Female (MUSM-ENT 0511867) (Figures 3, 16G, 17B): Total length: 28.4 , carapace length 13.0 , width 12.0 , chelicerae with 11-12 teeth on promargin. Cheliceral teeth pattern from basal end: right side: vvvvvvv-v-vVVV, 9 small and 3 big teeth. Left side: vvvvvv-VvVVV, 7 small

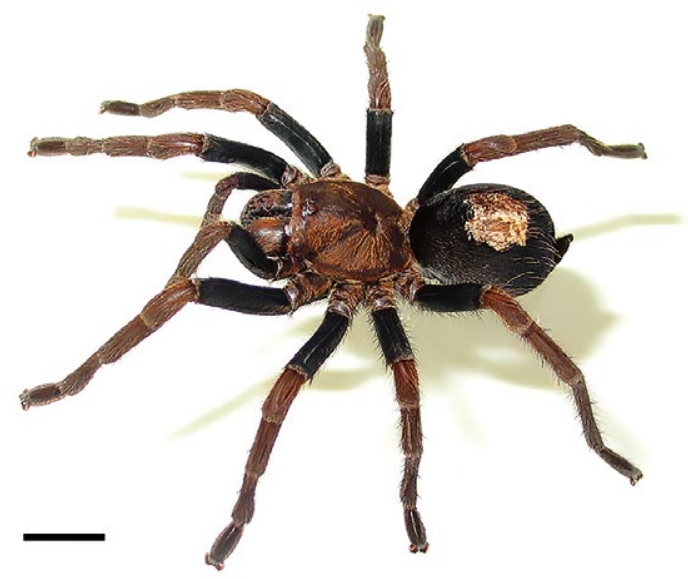

Figure 2. Cyriocosmus giganteus Kaderka 2016, female (MUSM-ENT 0511862) from Peru, Loreto, EBQB. Scale bar= $10 \mathrm{~mm}$. (photo by R. Kaderka) 
and 4 big teeth. Anterior eye row procurved, posterior eye row recurved. Eye sizes and interdistances (Figure 3C): AME 0.57 (circular), ALE 0.49 (oval), PME 0.31 (oval), PLE 0.42 (oval), AME-AME 0.26, AME-ALE 0.20, PME-PME 1.09, PME-PLE 0.04, ALE-PLE 0.16, AME-PME 0.14 , OQ length 1.07, width 2.21. Ocular tubercle elevated, length 1.56 , width 2.21. Clypeus narrow, width 0.156 . Fovea transverse, deep, straight, width 1.83, 8.91 from anterior edge of carapace. Labium length 2.26 , width
2.54, anterior half with 88 cuspules, maxillae with 208221 cuspules (Figure 3D). Labiosternal sigilla joined. Ventral maxilla distally with sparse short spiniform setae. Sternum length 6.62 , width 5.60, with three visible pairs of sternal sigilla located near coxae III (length 0.75 , 0.75 from edge of sternum), coxae II (length $0.49,0.60$ from edge of sternum) and coxae I (length $0.36,0.52$ from edge of sternum) (Figure 3B). Leg pattern: IV $>$ I $>$ II $>$ III. All leg segments uniform.

Table 1. Cyriocosmus giganteus Kaderka 2016, female (MUSM-ENT 0511867). Lengths of palpal and leg segments.

\begin{tabular}{lcccccc}
\hline & Femur & Patella & Tibia & Metatarsus & Tarsus & Total \\
\hline Palp & 6.9 & 5.0 & 4.8 & - & 5.3 & 22.0 \\
Leg I & 10.3 & 6.2 & 7.8 & 6.5 & 5.3 & 36.1 \\
Leg II & 9.1 & 5.6 & 6.2 & 6.0 & 5.0 & 31.9 \\
Leg III & 7.6 & 4.8 & 4.9 & 6.2 & 4.6 & 28.1 \\
Leg IV & 10.0 & 5.4 & 7.4 & 9.1 & 5.2 & 37.1 \\
\hline
\end{tabular}
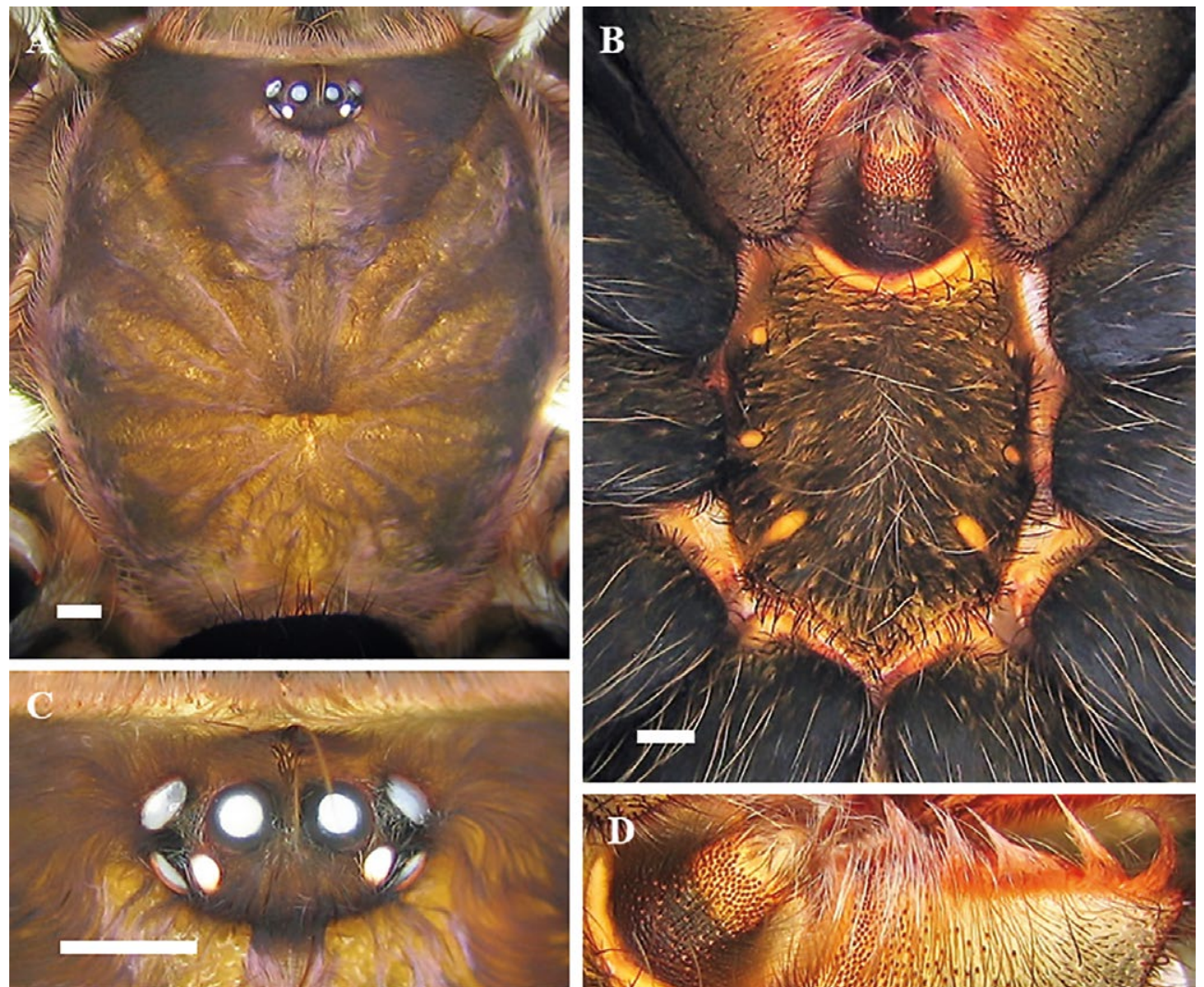

$\mathbf{E}$
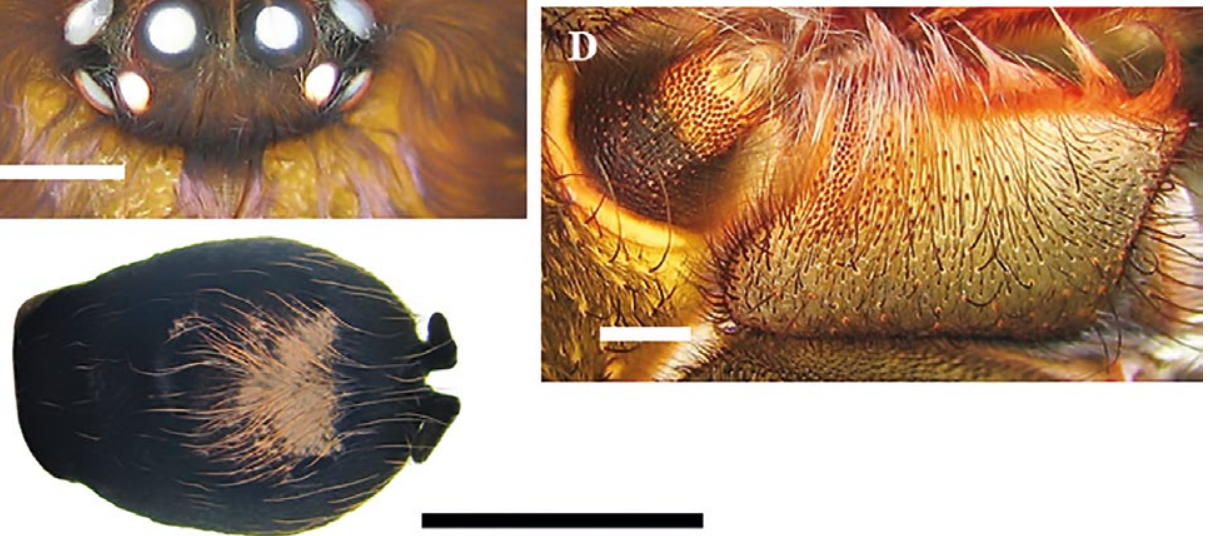

Figure 3. Cyriocosmus giganteus Kaderka 2016, female (MUSM-ENT 0511867) from Peru, Loreto, EBQB. A. Carapace, dorsal view. B. sternum, labium, coxae and maxillae, ventral view. C. Ocular tubercle, dorsal view. D. Labium and left maxilla, ventral view. E. Abdomen without striped pattern, dorsal view. Scale bar $=1 \mathrm{~mm}$ (Figures 3A-D). Scale bar= 10 mm (Figure 3E). (photos by R. Kaderka) 
Scopulae: All tarsi 100\% densely scopulate, metatarsi I 70\%, metatarsi II 60\%, metatarsi III 40\%, metatarsi IV 25\% scopulate. Tarsal scopulae I, II undivided, in tarsi III divided by a narrow longitudinal band of setae, in tarsi IV divided by a wide longitudinal band of setae. Denticulation pattern of paired tarsal claws on right leg (prolateral / retrolateral row): I 0/0, II 0/0, III 0/0, IV 0/0.

Spination: femora I p 0-0-1, II p 0-0-1, III 0 , IV 0 and femora of palps p $0-0-1$; patellae I-IV and patellae of palps 0 ; tibiae I v 0-0-2 (apical), II v 0-0-1 (apical), $\mathrm{p}$ 0-1-0, III v 0-0-2 (apical), p 1-1-0, r 1-1-1, IV v 0-0-3 (apical), p 0-1-0, r 1-1-0 and tibiae of palps v 0-0-3 (apical); metatarsi I v 0-1-2 (apical), II v 1-0-3 (apical), p 0-1-0, III v 0-0-3 (apical), p 2-1-2, r 0-1-1, IV v 0-2-1-3 (apical), $p$ $0-1-1, r$ 0-1-1-1, tarsi I-IV and tarsi of palps 0 .

Spermathecae (Figure 16G, 17B): two separated spiral seminal receptacles, distally terminated with globular extension, basally with convex, weakly sclerotized plates.

Abdomen: urticating setae of type III are located in central glossy patch. PLS: length 7.02, basal segment 2.34, middle segment 1.68, apical segment 3.00, all digitiform. PMS: 1.23.

Coloration and covering setae: dorsal view (Figures 3A, 3E): carapace uniformly bronze, without dark caput, coxae and trochantera brown, chelicerae brown, femora black, patellae, tibiae, metatarsi and tarsi brown, intermixed with long, pale setae. Patellae I, II, palpal patella, femora I-IV, palpal femora, tibiae I-IV and palpal tibia with two distinct parallel longitudinal stripes without covering setae, patellae III, IV with one such diagonal stripe. Retrolateral face of femora III and IV with one longitudinal stripe without covering setae. Abdomen (Figure $3 \mathrm{E})$ covered with short black setae, intermixed with long, pale setae in posterior part, except for central light brown glossy patch. Length of central patch: 5.9 , width 6.7. Ventral view: labium and maxillae black, sternum black, coxae, trochantera and femora black, intermixed with long pale setae, patellae, tibiae and metatarsi brown, in- termixed with long rufous setae. Abdomen black, except for booklungs and anterior part above epigastric scutum, which are brown and light brown. Spinnerets black.

Variability: The variability in the shape of spermathecae on Figures 16G, 17.

Coloration during ontogeny: The first nymphal stages (according to Foelix 2011), with carapace length 2.6 $\mathrm{mm}$ and larger, carapace and femora are black, rest of legs are light brown, abdomen is dark brown to black, intermixed with long pale setae.

Notes: In the type locality, Cyriocosmus giganteus is living in sympatry with $C$. sellatus, Proshapalopus sp., Cyclosternum sp., Megaphobema velvetosoma Schmidt 1995 and Pamphobeteus sp. (all belonging to Theraphosinae).

\section{Cyriocosmus sellatus (Simon 1889)}

$$
\text { (Figures 5-9, 18, 19, Table 2) }
$$

\section{Hapalopus sellatus Simon 1889: 218.}

Cyriocosmus sellatus: Simon 1903: 929, figure 1082. Schiapelli \& Gerschman de Pikelin 1973: 67, figures 16-22. Pérez-Miles et al. 1996: 48, figure 16. Pérez-Miles 1998: 100. Fukushima et al. 2005: 11, figures 19, 20, 32, 49. Kaderka 2016: 44-45, figures 21, 26c-d, 32e-f.

Types: Female holotype (MNHN 8102, newly MNHN AR 12330), male allotype (MNHN 8102, newly MNHN AR 12331), immature male (MNHN 8102, newly MNHN AR 12332) from Brazil, Upper Amazonas, São Paulo de Olivença, Fonte Boa. Male allotype examined. The designation of the types follows Schiapelli \& Gerschman de Pikelin (1973) and differs from the records in MNHN made by Gerschman de Pikelin \& Schiapelli, according to which the male allotype is designated as a male holotype (MNHN AR 12331) and the female holotype as a female allotype (MNHN AR 12330). Both types were dedicated from Museo Argentino de Ciencias Naturales by Berta Gerschman de Pikelin and Rita Schiapelli.

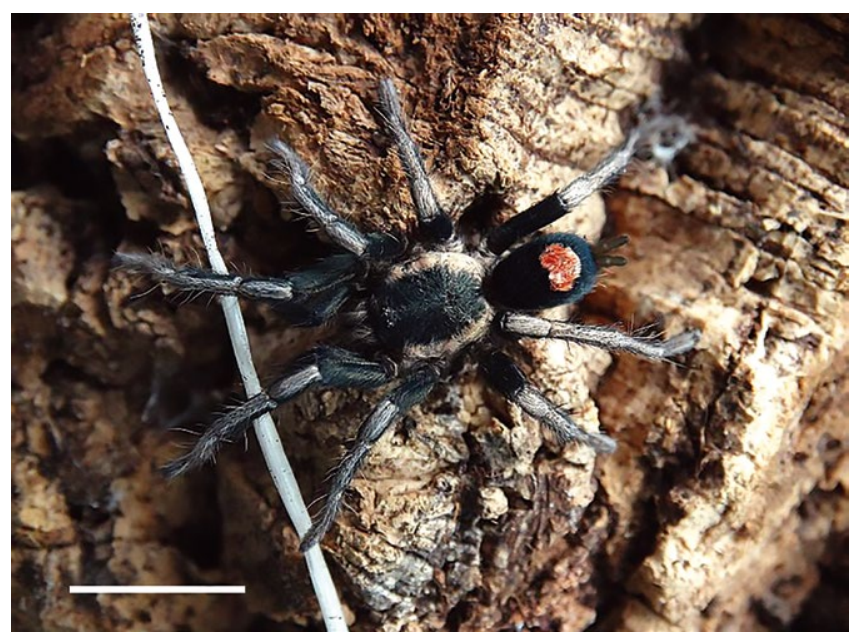

Figure 5. Cyriocosmus sellatus (Simon 1889), male (MUSM-ENT 0511861, formerly RKCP 0594) from Peru, Loreto, Reserva Nacional Allpahuayo - Mishana, dorsal view. Scale bar $=10 \mathrm{~mm}$. (photo by Hans-W. Auer)
Figure 4. Cyriocosmus giganteus Kaderka 2016, juvenile specimen (car. 2.0) from Peru, Loreto, EBQB. First nymphal stage without patch of urticating setae. Scale bar $1 \mathrm{~mm}$. (photo by R. Kaderka) 
Diagnosis: The species can be distinguished from all other congeners by lacking the striped pattern on dorsal abdomen (Kaderka 2016: figures 21c-d) and by the black carapace with two pale and wide lateral stripes (Kaderka 2016: figure 21a), in combination with the yellowish longitudinal stripes on the dorsal face of the legs in females. The males have a long paraembolic apophysis and indistinct prolateral superior keel in palpal bulb (Figures 8C-D, 8E-F, 8G-H, 9A-B).

Distribution (Figures 18, 19): Known only from Brazil, Upper Amazonas, São Paulo de Olivença, Fonte Boa, from Peru, Loreto, Yanamono, $80 \mathrm{~km}$ east of Iquitos, and newly from Peru, Loreto, Estación Biologica Quebrada Blanco, $100 \mathrm{~km}$ south of Iquitos and from Peru, Loreto, Reserva Nacional Allpahuayo - Mishana, $10 \mathrm{~km}$ from Iquitos.

Male (MUSM-ENT 0511179) (Figures 6, 7, 8G, 8H): Total length: 10.9 , carapace length 5.9 , width 4.8 , chelicerae with 9 teeth on promargin. Cheliceral teeth pattern from basal end: right side: $\mathrm{V}-\mathrm{v}-\mathrm{v}-\mathrm{v}-\mathrm{V}-\mathrm{V}-\mathrm{V}-\mathrm{V}-\mathrm{V}, 3$ small and 6 big teeth. Left side: $\mathrm{V}-\mathrm{v}-\mathrm{V}-\mathrm{v}-\mathrm{V}-\mathrm{V}-\mathrm{V}-\mathrm{V}-\mathrm{V}, 3$ small and 6 big teeth. Anterior eye row procurved, posterior eye row recurved. Eye sizes and interdistances (Figure 6C): AME 0.36 (circular), ALE 0.29 (oval), PME 0.19 (oval), PLE 0.22 (oval), AME-AME 0.06, AME-ALE 0.07, PME-PME

Table 2. Cyriocosmus sellatus (Simon 1889), male (MUSM-ENT 0511179). Lengths of palpal and leg segments.

\begin{tabular}{|c|c|c|c|c|c|c|}
\hline & Femur & Patella & Tibia & Metatarsus & Tarsus & Total \\
\hline Palp & 2.9 & 1.8 & 2.3 & - & 1.0 & 8.0 \\
\hline Leg I & 4.7 & 2.9 & 3.7 & 3.5 & 2.8 & 17.6 \\
\hline Leg II & 4.1 & 2.4 & 2.9 & 2.8 & 2.5 & 14.7 \\
\hline Leg III & 3.6 & 2.0 & 2.3 & 2.9 & 2.3 & 13.1 \\
\hline Leg IV & 4.9 & 2.3 & 4.0 & 4.6 & 2.8 & 18.6 \\
\hline
\end{tabular}
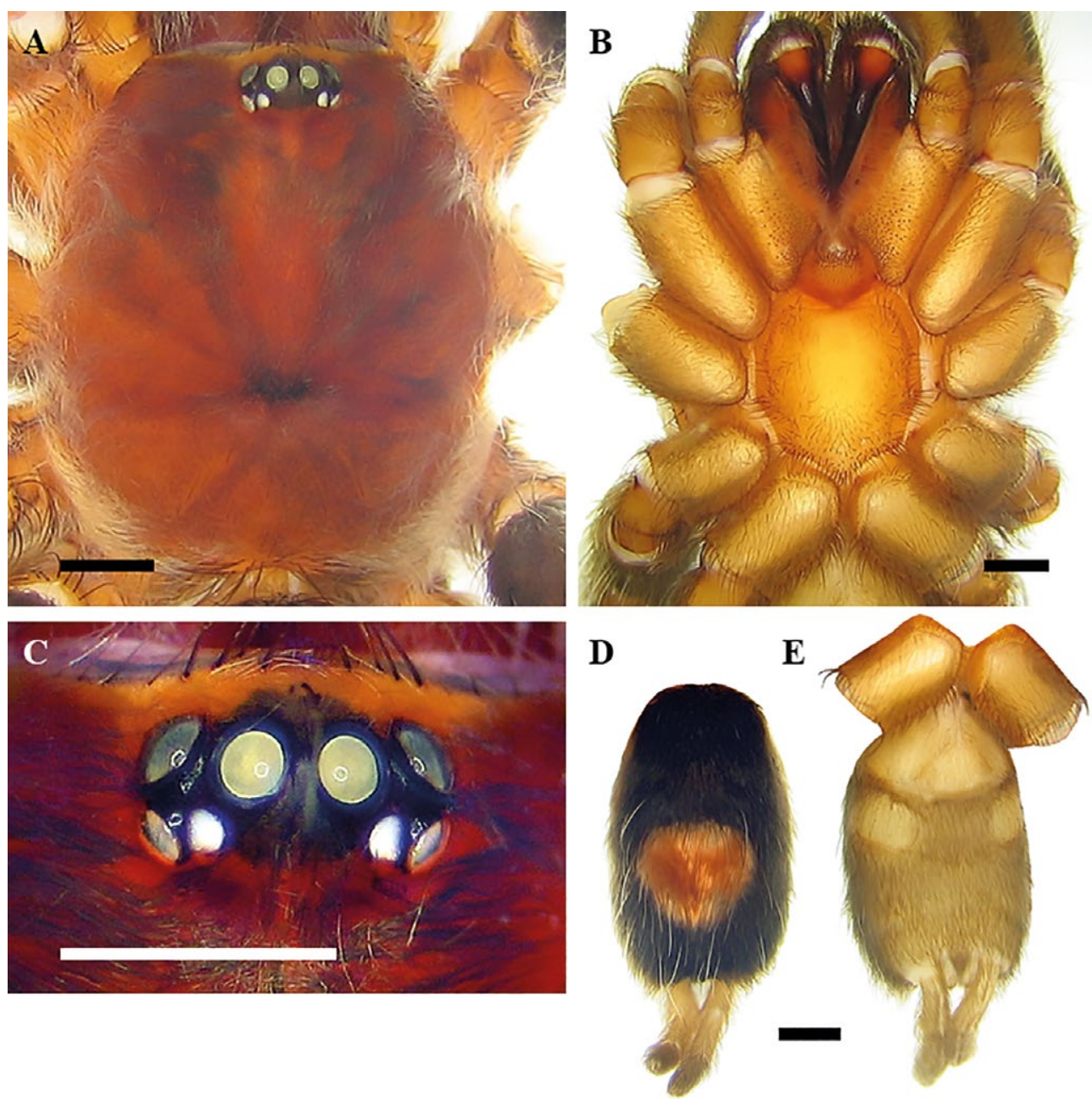

Figure 6. Cyriocosmus sellatus (Simon 1889), male (MUSM-ENT 0511179) from Peru, Loreto, Estación Biologica Quebrada Blanco. A. Carapace and coxae, dorsal view. B. Sternum, labium, maxillae, coxae and trochantera, ventral view. C. Ocular tubercle, dorsal view. D. Abdomen without striped pattern, dorsal view. E. Abdomen, ventral view. Scale bar $=1 \mathrm{~mm}$. (photos by R. Kaderka) 
0.52, PME-PLE 0.03, ALE-PLE 0.08, AME-PME 0.03, OQ length 0.556 , width 1.144 . Ocular tubercle: length 0.924 , width 1.144. Clypeus absent. Fovea transverse, slightly procurved, width $0.96,3.71$ from anterior edge of carapace. Labium length 0.74 , width 1.21 , anterior third with 51 cuspules, maxillae with $145-163$ cuspules in basal half. Sternum length 2.77 , width 2.38 , three pairs of hardly visible sternal sigilla located near coxae III, coxae II and coxae I. Leg pattern: IV>I $>$ II $>$ III. Incrassate leg segments: femur III.

Scopulae: All tarsi 100\% densely scopulate, metatarsi I 60\%, metatarsi II 50\%, metatarsi III 40\%, metatarsi IV 10\% scopulate. Tarsal scopulae I, II undivided, in tarsi III divided by a longitudinal band of setae, in tarsi IV divided by a wide longitudinal band of setae. Denticulation pattern of paired tarsal claws on right leg (prolateral / retrolateral row): I 0/0, II 0/0, III 0/0, IV 0/0.

Spination: femora I p 0-0-1, II p 0-0-2, III d 0-0-2, IV r 0-0-1 and femora of palps p 0-0-1; patellae I-IV and patellae of palp 0; tibiae I v 0-1-1 (apical), p 1-0-1, II v 0-1-2 (apical), p 0-1-0, III v 2-1-1 (apical), p 0-1-1, r 1-0-1, IV v 2-2-4 (apical), p 1-1-0, r 1-1-1 and tibiae of palps p 0-01; metatarsi I v 0-0-1 (apical), II v 0-1-2 (apical), p 0-1-0, III v 1-2-2 (apical), p 1-1-1, r 0-1-1, IV v 3-2-3 (apical), $p$ $1-1-1$, r $0-1-1$, tarsi I-IV and tarsi of palps 0 .

Palpal organ as in Figures 8G and $8 \mathrm{H}$, embolus with long PA, smooth PS keel weakly developed and fused with PA. Tegulum with TP projecting prolaterally. Pro-

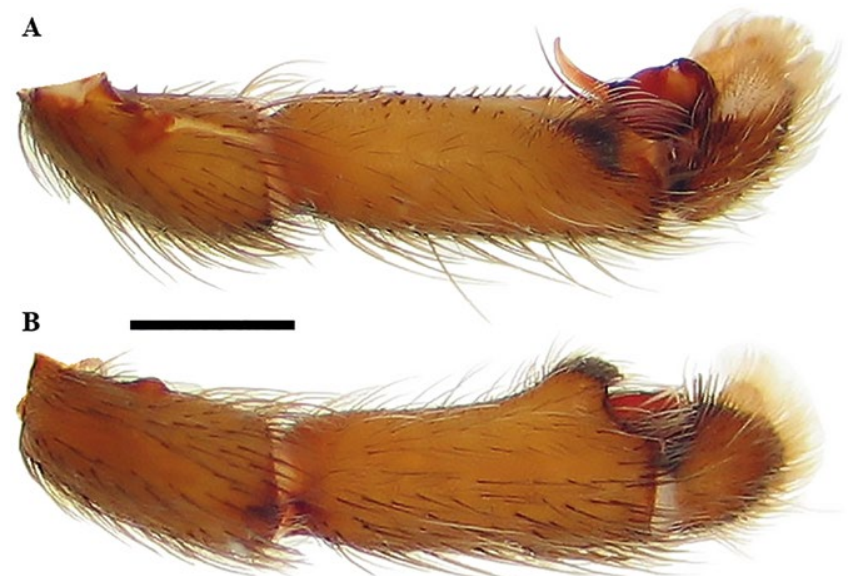

C

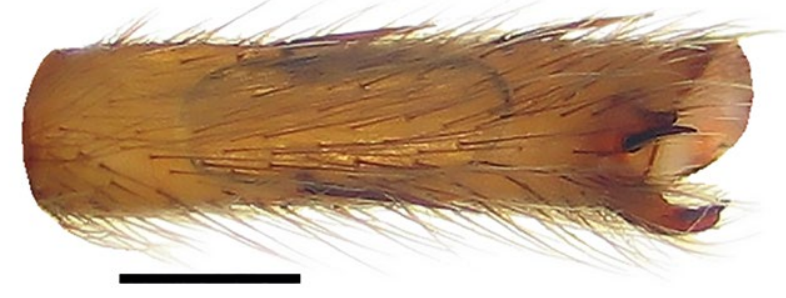

Figure 7. Cyriocosmus sellatus (Simon 1889), male (MUSM-ENT 0511179) from Peru, Loreto, Estación Biologica Quebrada Blanco. A-B. Morphology of left palpal tibia, retrolateral view (A), dorsoretrolateral view (B). C. Left tibia I with two unequal apophyses, prolaterally ventral view. Scale bar $=1 \mathrm{~mm}$. (photos by R. Kaderka). lateral cymbial lobe distinctly larger than retrolateral one. Retrolateral face of cymbium with basal field of spiniform setae. Retrolateral face of palpal tibia with distinct subapical protuberance covered with cluster of numerous spiniform setae (Figures 7A, 7B). Two unequal subapical apophyses are present on tibia I (Figure 7C): longer retrolateral tibial apophysis with stout spine at apex and shorter prolateral tibial apophysis with single, well-developed retrolateral spine overreaching the apex. Metatarsus I not sigmoidly curved and without basal or median protuberance on retrolateral face. Metatarsus I flexion is between both tibial apophyses.

Abdomen: urticating setae of type III are located in central glossy patch. PLS: length 3.88 , basal segment 1.56, middle segment 0.99 , apical segment 1.33 , all segments long, digitiform. PMS: 0.60 .

Coloration and covering setae (damaged by a longterm preservation in alcohol): dorsal view (Figures 6A, 6D): carapace brown with two lateral stripes covered with whitish pubescence, without dark caput, coxae and trochantera yellowish brown, chelicerae reddish-brown,
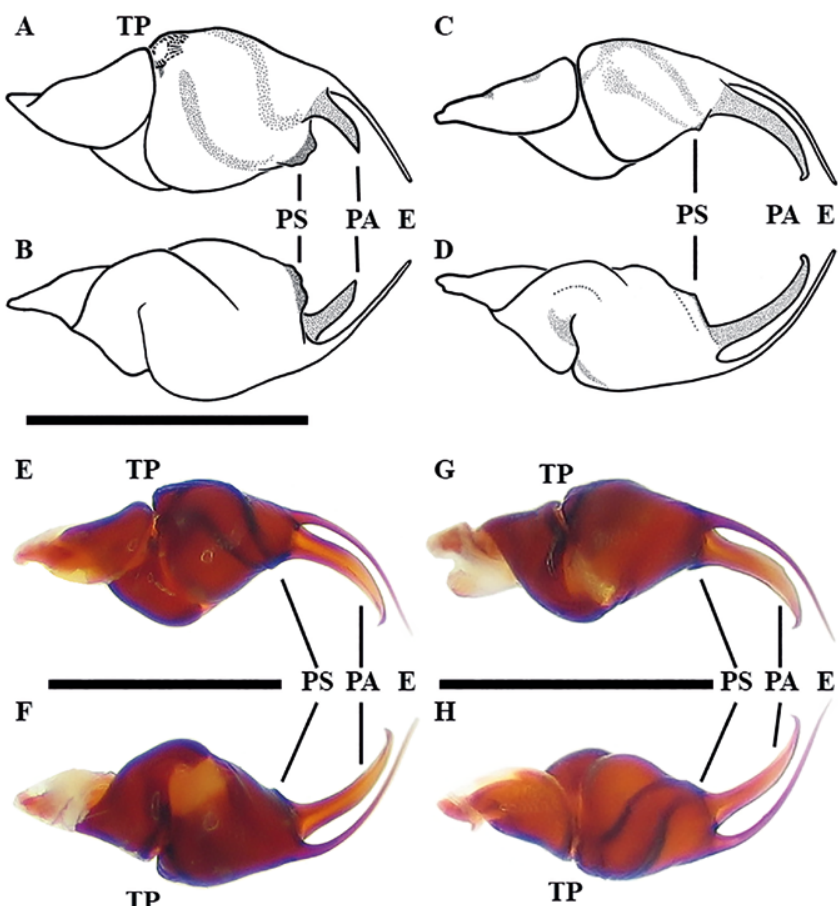

Figure 8. A-B. Cyriocosmus ritae Pérez-Miles 1998, male (NMPC P6A-5731, formerly RKCP 0347) from Peru, Iquitos, the Amazon River, Las Palmas. Morphology of right male palpal bulb, prolateral view (A), retrolateral view (B). C-D. Cyriocosmus sellatus (Simon 1889), male allotype (MNHN AR 12331, formerly MNHN 8102) from Upper Amazonas. Morphology of right male palpal bulb, prolateral view (C), retrolateral view (D). E-F. Cyriocosmus sellatus (Simon 1889), male (MUSM-ENT 0504034) from Peru, Loreto, Yanamono, $80 \mathrm{~km}$ east from Iquitos. Morphology of right male palpal bulb, prolateral view (E), retrolateral view (F). G-H. Cyriocosmus sellatus (Simon 1889), male (MUSM-ENT 0511179) from Peru, Loreto, Estación Biologica Quebrada Blanco. Morphology of left male palpal bulb, retrolateral view (G), prolateral view (H). Scale bar $=1 \mathrm{~mm}$. (photos by R. Kaderka) 
and covered with whitish pubescence, femora black, patellae, tibiae, metatarsi and tarsi brown, intermixed with long setae. Patellae I, II and palpal patella with two distinct longitudinal parallel stripes without covering setae, patellae III, IV with two unequal diagonal stripes. Abdomen covered with short black setae, intermixed with long setae, except for red central oval patch. Length of central patch: 1.72, width 2.01. Ventral view (Figures 6B, 6E): labium, maxillae, sternum, coxae and trochantera yellowish-brown, femora dark brown, patellae, tibiae and metatarsi brown. Abdomen ventrally yellowish brown, without dark longitudinal band. Spinnerets yellowish brown.

Notes: Simon (1889) mentioned in the original description that females of $C$. sellatus have yellowish longitudinal stripes on the dorsal faces of the legs ("supra vitta fulvo-pilosa ornati") and pointed out the presence of two pale and wide lateral stripes on the carapace as well ("vitta marginalli lata roseo-argenteopilosa laete decoratus"). Due to the long-term preservation in alcohol all types of $C$. sellatus are uniformly light brown. Kaderka (2016) included these traits into the diagnosis of this species and identified a small Cyriocosmus species from Yanamono, Loreto in Peru as $C$. sellatus based on the congruent shape of male palpal bulb, developed retrolateral process on palpal tibia, the presence of two pale lateral stripes on carapace and uniformly coloured abdomen without stripes. During the following studies the author examined another two males of $C$. sellatus from two new localities: the first one was from Rio Blanco, tributary of Rio Tahuyao (approximatelly $100 \mathrm{~km}$ south from Iquitos), the second one was found in Reserva Nacional Allpahuayo

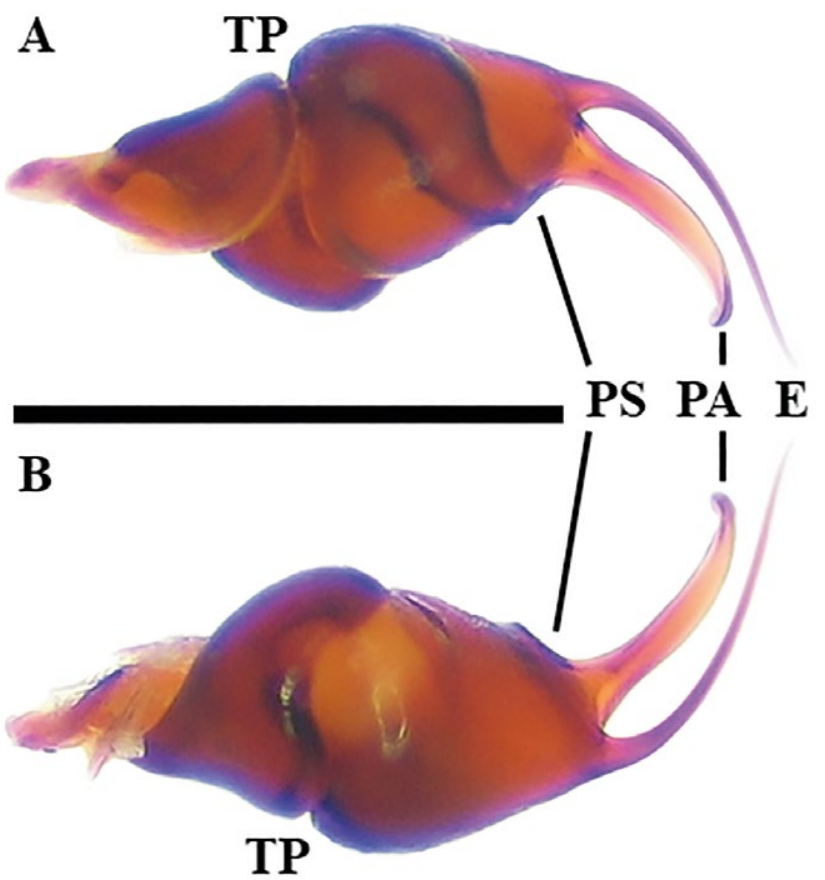

Figure 9. Cyriocosmus sellatus (Simon 1889), male (MUSM-ENT 0511861 , formerly RKCP 0594) from Peru, Loreto, Reserva Nacional Allpahuayo - Mishana. Morphology of right male palpal bulb, prolateral view (A), retrolateral view (B). Scale bar= $1 \mathrm{~mm}$. (photos by R. Kaderka)
- Mishana (approximatelly $10 \mathrm{~km}$ west from Iquitos) and this latter specimen represented the only live specimen available to author. However, the coloration of longitudinal stripes on legs is whitish or greyish and differs from the coloration mentioned in the original description. Unfortunatelly, we do not know if the coloration mentioned in the original description refers to the live specimen or to the specimen preserved in alcohol. A long-term preservation in alcohol might cause a colour change.

Variability: The variability in morphology of male palpal bulbs is shown on Figures 8C-D, 8E-F, 8G-H, 9A-B.

\section{Cyriocosmus paredesi sp. nov.}

\section{(Figures 10, 11, 18, 19, Table 3)}

Types: Male holotype (MUSM-ENT 0507080) from Peru, Amazonas, Quebrada Putuiman, Rio Marañon, $4^{\circ} 22^{\prime} 24.85^{\prime \prime S}, 76^{\circ} 56^{\prime} 04.22$ 'W, 311 m a.s.l., August 2627, 2010, W. Paredes col.

Etymology: The specific name is a patronym in honour of Williams Paredes, who found this new species in the Amazon rainforest in northern Peru.

Diagnosis: Cyriocosmus paredesi sp. nov. can be distinguished from all other congeners by the black carapace with narrow whitish lateral stripes, abdomen without stripes, patellae covered with whitish setae and by the short paraembolic apophysis in male palpal bulb, not fused with well-developed PS keel.

Distribution (Figures 18, 19): Known only from the type locality.

Male (MUSM-ENT 0507080) (Figures 10, 11): Total length: 14.2 , carapace length 7.6 , width 5.9 , chelicerae with 9 teeth on promargin. Cheliceral teeth pattern from basal end: right side: $\mathrm{V}-\mathrm{V}-\mathrm{V}-\mathrm{v}-\mathrm{V}-\mathrm{V}-\mathrm{V}-\mathrm{V}-\mathrm{V}, 4$ small and 5 big teeth. Left side: $\mathrm{V}-\mathrm{V}-\mathrm{V}-\mathrm{v}-\mathrm{v}-\mathrm{v}-\mathrm{v}-\mathrm{V}-\mathrm{V}, 4$ small and 5 big teeth. Anterior eye row slightly procurved, posterior eye row slightly recurved. Eye sizes and interdistances (Figure 10C): AME 0.31 (circular), ALE 0.39 (oval), PME 0.23 (oval), PLE 0.31 (oval), AME-AME 0.13, AME-ALE 0.05, PME-PME 0.62, PME-PLE 0.01, ALE-PLE 0.05, AME-PME 0.04 , OQ length 0.67 , width 1.30 . Ocular tubercle: length 1.07, width 1.30. Clypeus absent. Fovea transverse, procurved, width $0.9,5.0$ from anterior edge of carapace. Labium length 0.91 , width 1.56 , anterior third with 79 cuspules, maxillae with 251-255 cuspules in basal half. Sternum length 3.7 , width 2.8 , three pairs of sternal sigilla located near coxae III (length $0.26,0.23$ from edge of sternum), coxae II (length $0.13,0.18$ from edge of sternum) and coxae I (length $0.05,0.10$ from edge of sternum). Leg pattern: IV>I>II>III. Incrassate leg segments: femur III.

Scopulae: All tarsi 100\% densely scopulate, metatarsi I, II 40\%, metatarsi III 30\%, metatarsi IV 15\% scopulate. Tarsal scopulae I, II undivided, tarsal scopulae III divided by a longitudinal row of setae, tarsal scopulae IV divided by a longitudinal band of setae. Denticulation pattern of paired tarsal claws on right leg (prolateral / retrolateral row): I 3/2-3, II 2/2, III 3/2, IV 2-3/3. 
Table 3. Cyriocosmus paredesi sp. nov., male holotype. Lengths of palpal and leg segments.

\begin{tabular}{lllllll}
\hline & Femur & Patella & Tibia & Metatarsus & Tarsus & Total \\
\hline Palp & 3.9 & 2.3 & 3.0 & - & 1.7 & 3.9 \\
Leg I & 4.7 & 3.5 & 4.5 & 4.5 & 3.3 \\
Leg II & 4.4 & 3.2 & 4.1 & 4.2 & 3.2 \\
Leg III & 5.0 & 2.7 & 3.2 & 6.9 & 2.9 \\
Leg IV & 6.5 & 3.1 & 5.3 & 3.7 & 25.5 \\
\hline
\end{tabular}
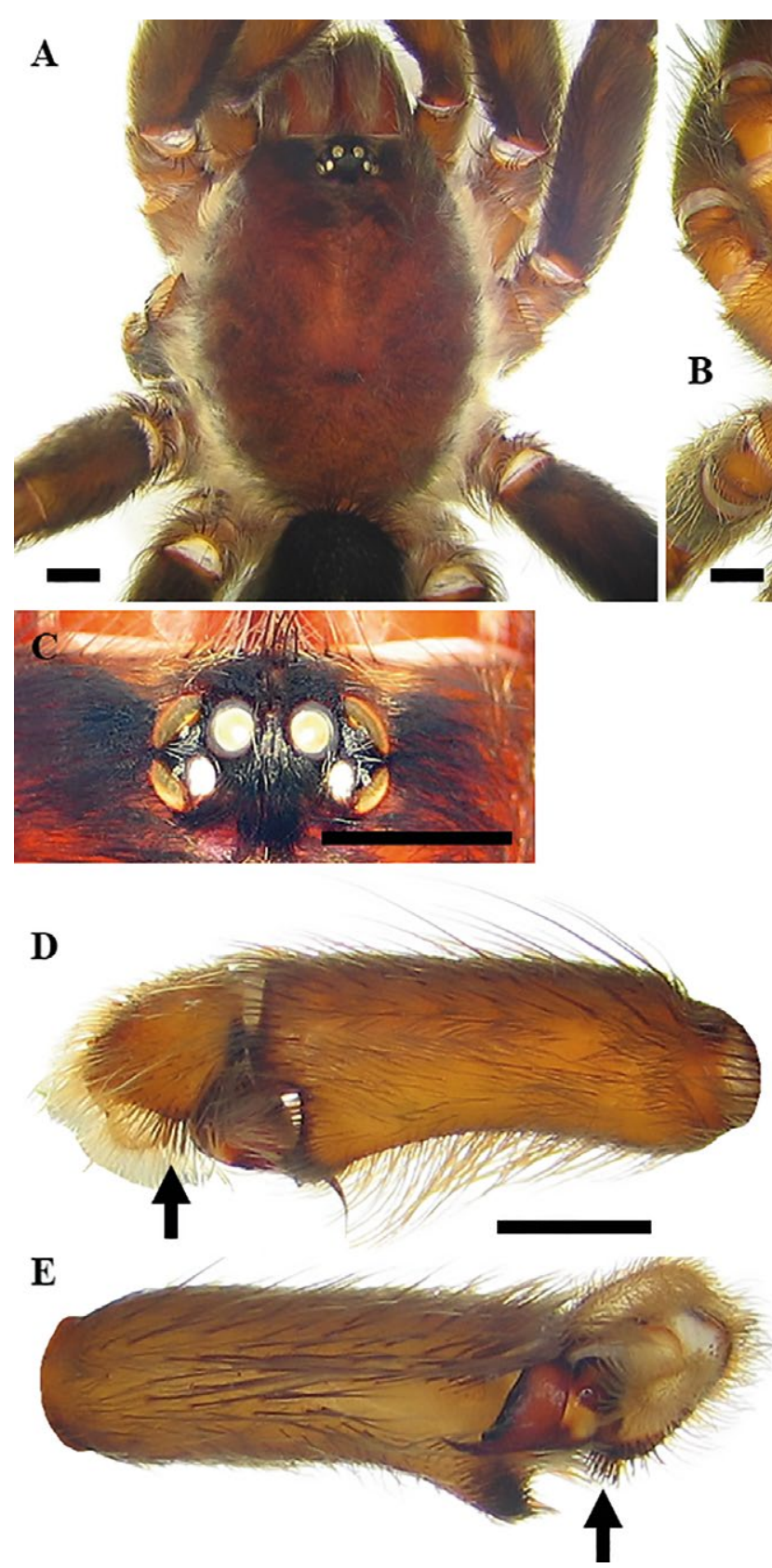

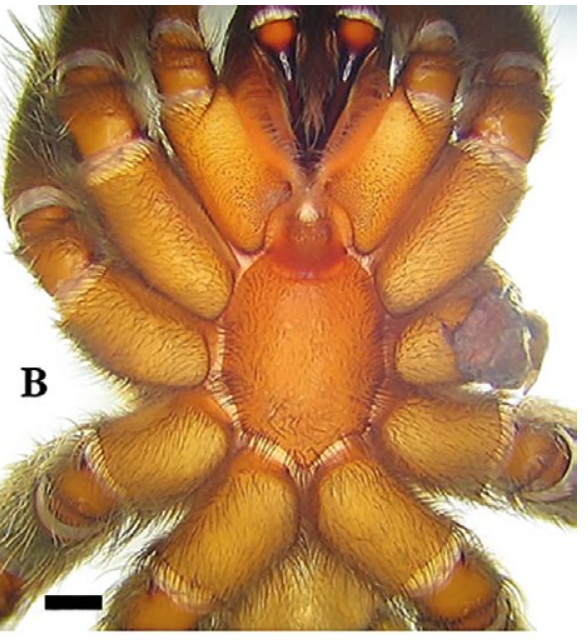

$\mathbf{F}$

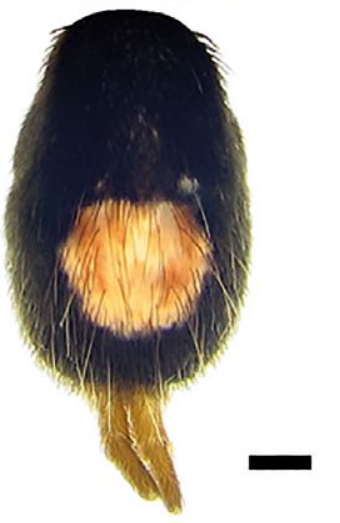

G

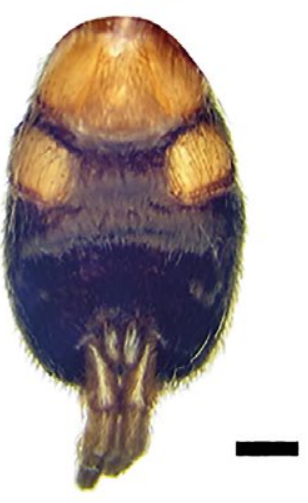

Figure 10. Cyriocosmus paredesi sp. nov., male holotype (MUSM-ENT 0507080) from Peru, Amazonas, Quebrada Putuiman, Rio Marañon. A. Carapace, coxae, trochantera and femora, dorsal view. B. Sternum, labium, maxillae, coxae and trochantera, ventral view. C. Ocular tubercle, dorsal view. D. Cymbium and tibia of left palp, retrolateral view. E. Cymbium and tibia of left palp, ventral view. Arrows show spiniform setae on retrolateral lobe of cymbium. F. Abdomen without striped pattern, dorsal view. G. Abdomen, ventral view. Scale bar $=1 \mathrm{~mm}$. (photos by R. Kaderka) 
Spination: femora I d 0-0-1, II d 0-0-1, III d 0-1-2, IV 0 and femora of palps 0 ; patellae I-IV and patellae of palps 0; tibiae I r 0-0-1 (apical), v 0-1-0, II p 0-0-1, v 0-1-3, III p 1-1-0, r 1-1-1, v 1-3-3 (apical), IV p 1-0-0, r 1-0-1, v 1-3-2 (apical) and tibiae of palps p 0-1-0; metatarsi I v 0-0-1 (apical), II v 0-1-1 (apical), III p 1-1-1-1, r 0-1-1, v 1-1-2 (apical), IV p 1-1-1-1, r 0-1-1-1, v 1-1-2, tarsi I-IV and tarsi of palps 0 .

Palpal organ as in Figures $11 \mathrm{~A}-\mathrm{C}$, embolus with short PA and smooth developed PS keel. Tegulum with distinct granulated TP, projecting prolaterally. Retrolateral face of cymbium with basal field of spiniform setae, prolateral cymbial lobe distinctly larger than retrolateral lobe. Retrolateral face of palpal tibia with developed subapical process, apically covered with numerous spiniform setae (Figures 10D, 10E). Two unequal subapical apophyses are present on tibia I: longer retrolateral tibial apophysis with short and stout apical spine and shorter prolateral tibial apophysis with single, retrolateral spine at base, approximately $80 \%$ of the length of prolateral tibial apophysis long. Metatarsus I not sigmoidly curved and without basal or median protuberance on retrolateral face. Metatarsus I flexion is between both tibial apophyses.

Abdomen: urticating setae of type III are located in central glossy patch. PLS: length 4.39 , basal segment 1.33, middle segment 1.34 , apical segment 1.72 , all digitiform. PMS: 0.73 .

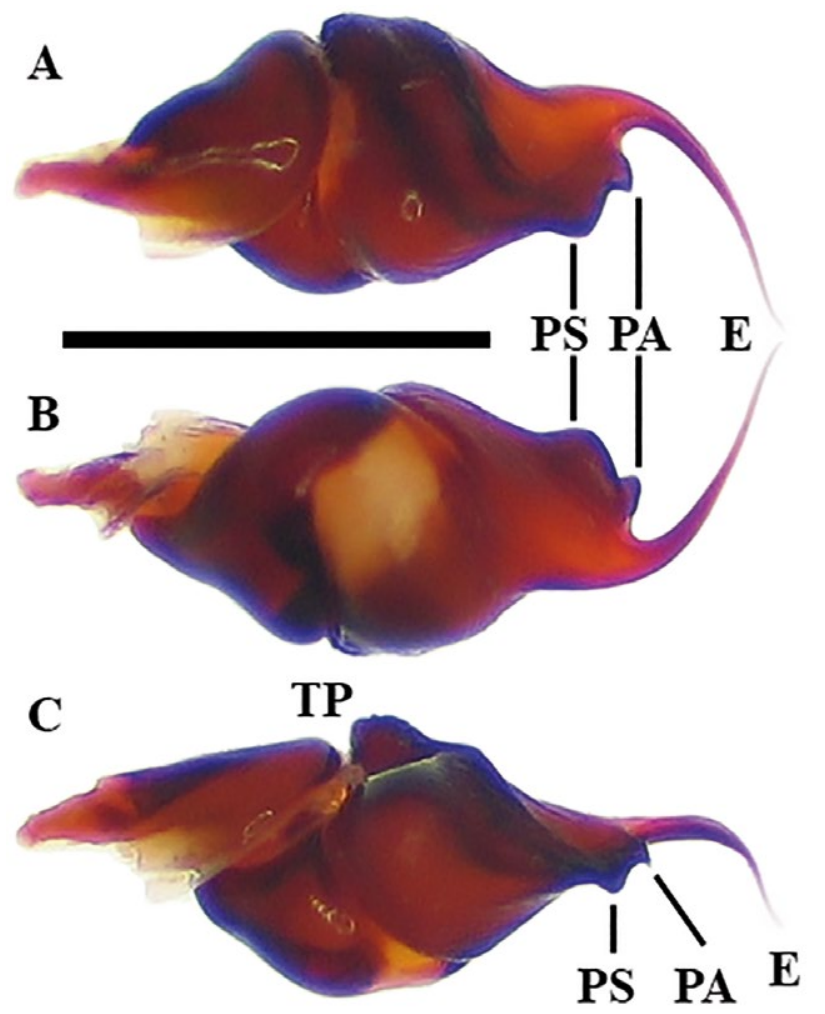

Figure 11. Cyriocosmus paredesi sp. nov., male holotype (MUSM-ENT 0507080) from Peru, Amazonas, Rio Marañon. Morphology of right male palpal bulb, prolateral view $(A)$, retrolateral view $(B)$, ventral view (C). Scale bar $=1 \mathrm{~mm}$. (photos by R. Kaderka)
Coloration and covering setae (damaged by preservation in alcohol): dorsal view (Figures 10A, 10F): carapace black with narrow whitish lateral stripes, coxae, trochantera reddish-brown, chelicerae partly covered with pale pubescence, femora black, patellae with whitish longitudinal stripe, tibiae, metatarsi and tarsi dark grey, intermixed with long, pale setae. Patellae I, II and palpal patella with two distinct longitudinal stripes covered with whitish pubescens, patellae III, IV with single diagonal stripe covered with such pubescens. Abdomen covered with short black setae, intermixed with long, pale setae in posterior part, except for central reddish-brown and almost circular patch. Length of central patch: 2.49, width 2.44. Ventral view (Figures 10B, 10G): labium, sternum, coxae, maxillae and trochantera reddish-brown, femora black, patellae, tibiae and metatarsi brown. Abdomen ventrally black, without dark longitudinal band. Spinnerets grey.

Female: Unknown.

\section{Cyriocosmus foliatus sp. nov.}

\section{(Figures 12-15, 18, 19, Table 4)}

Types: Male holotype (MUSM-ENT 0511875) from Peru, Loreto, Umaral near Iquitos, $03^{\circ} 42.076^{\prime} \mathrm{S}$, $73^{\circ} 05.890^{\prime} \mathrm{W}, 101 \mathrm{~m}$ a.s.l., October 20, 2017, Nolberto Ahuanari col.

Etymology: The specific name is derived from the Latin word folium, leaf, and refers to the shape of urticating setal patch on the dorsum of the abdomen, which is similar to oak leaf.

Diagnosis: Cyriocosmus foliatus sp. nov. can be distinguished from all other congeners by its uniformly coloured carapace and abdomen and by the short paraembolic apophysis in the male palpal bulb, not fused with PS keel, and by the presence of A keel.

Distribution (Figures 18, 19): Known only from Peru, Maynas province in Loreto Department, Umaral near Iquitos. The region is originally covered with lowland rainforest.

Male (MUSM-ENT 0511875) (Figures 12-15): Total length: 17.3 , carapace length 7.2 , width 5.7 , chelicerae

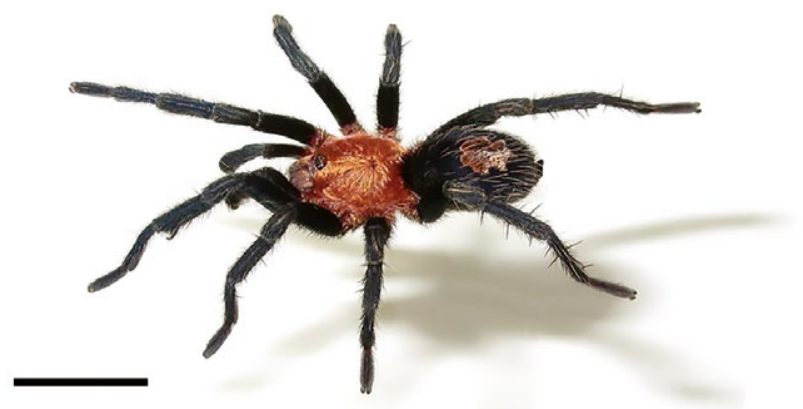

Figure 12. Cyriocosmus foliatus sp. nov., male holotype (MUSM-ENT 0511875) from Peru, Loreto, Iquitos, Umaral. Scale bar $=10 \mathrm{~mm}$. (photo by R. Kaderka) 
with 9 teeth on promargin. Cheliceral teeth pattern from basal end: right side: $\mathrm{v}-\mathrm{V}-\mathrm{V}-\mathrm{v}-\mathrm{v}-\mathrm{V}-\mathrm{V}-\mathrm{Vv}, 3$ small and 6 big teeth. Left side: V-V-V-v-v-V-V-Vv, 2 small and 7 big teeth. Anterior eye row procurved, posterior eye row recurved. Eye sizes and interdistances (Figure 13C): AME 0.35 (circular), ALE 0.31 (oval), PME 0.21 (oval), PLE 0.29 (oval), AME-AME 0.13, AME-ALE 0.05, PME-PME 0.47, PMEPLE 0.03, ALE-PLE 0.12, AME-PME 0.03, OQ length 0.68, width 1.14. Ocular tubercle: length 0.99 , width 1.14 . Clypeus absent. Fovea transverse, straight, deep, width $0.68,4.42$ from anterior edge of carapace. Labium length
0.94 , width 1.33 , anterior third with 51 cuspules, maxillae with 113-114 cuspules in basal half. Maxilla without spiniform setae. Sternum length 3.68, width 2.87, three pairs of sternal sigilla located near coxae III (length 0.26 , 0.23 from edge of sternum), coxae II (length $0.14,0.21$ from edge of sternum) and coxae I (length $0.13,0.14$ from edge of sternum). Leg pattern: IV > I > II > III. Incrassate leg segments: femur III.

Scopulae: All tarsi 100\% densely scopulate, metatarsi I-II 80\%, metatarsi III 50\%, metatarsi IV 25\% scopu-

Table 4. Cyriocosmus foliatus sp. nov., male holotype (MUSM-ENT 0511875). Lengths of palpal and leg segments.

\begin{tabular}{lccccc}
\hline & Femur & Patella & Tibia & Metatarsus & Tarsus \\
\hline Palp & 3.7 & 2.2 & 3.0 & - & 1.6 \\
Leg I & 6.0 & 3.4 & 4.5 & 4.5 & 3.4 \\
Leg II & 5.6 & 2.9 & 4.1 & 4.1 & 3.2 \\
Leg III & 4.9 & 2.6 & 3.2 & 4.3 & 3.3 \\
Leg IV & 6.4 & 2.9 & 5.3 & 6.4 & 3.7 \\
\hline
\end{tabular}
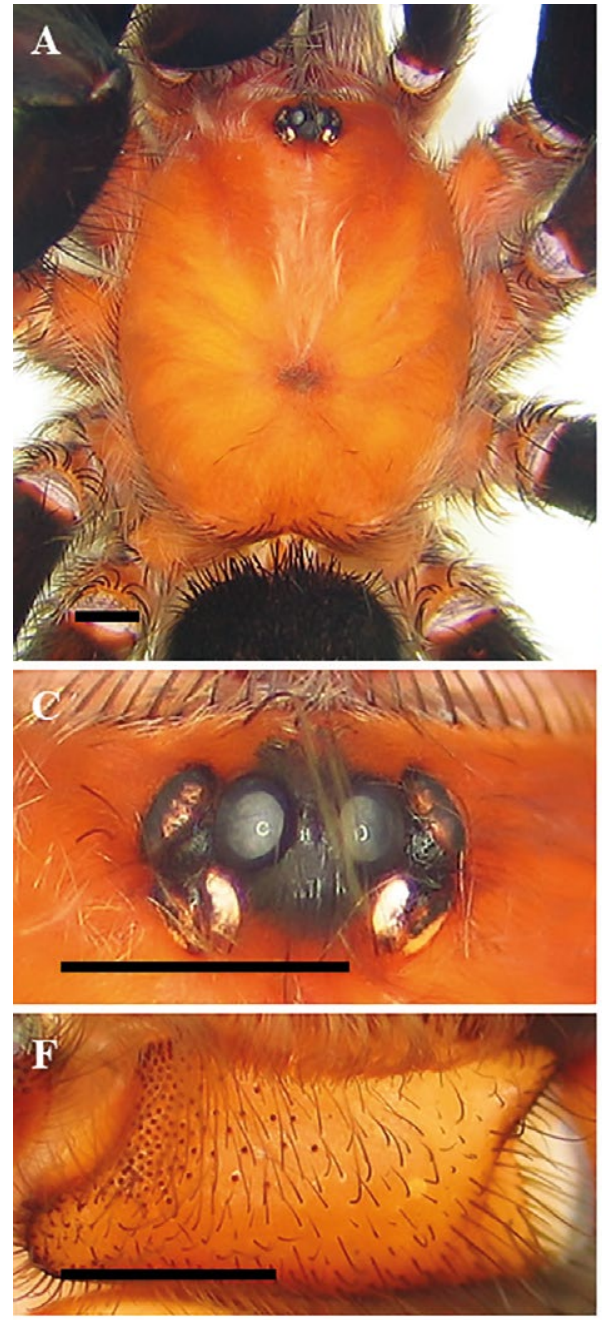
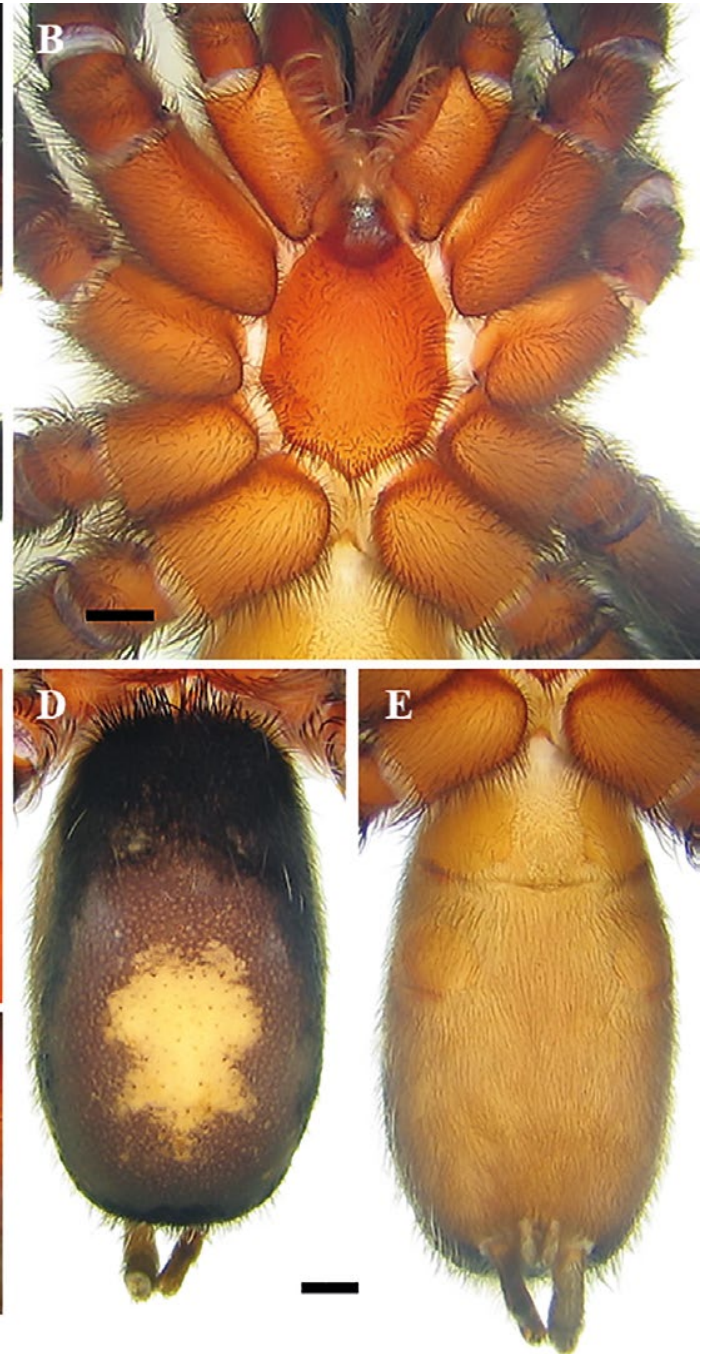

Figure 13. Cyriocosmus foliatus sp. nov., male holotype (MUSM-ENT 0511875) from Peru, Loreto, Iquitos, Umaral. A. Carapace, coxae and trochantera, dorsal view. B. Sternum, labium, maxillae, coxae and trochantera, ventral view. C. Ocular tubercle, dorsal view. D. Abdomen without striped pattern, dorsal view (without covering setae). E. Abdomen, ventral view. F. Left maxilla, ventral view. Scale bar $=1 \mathrm{~mm}$. (photos by R. Kaderka) 
late. Tarsal scopulae I, II undivided, in tarsi III divided by a narrow longitudinal band of setae, in tarsi IV divided by a wide longitudinal band of setae. Denticulation pattern of paired tarsal claws on right leg (prolateral / retrolateral row): I 0/0, II 0/0, III 0/0, IV 0/0.

Spination: femora I p 0-0-1, II p 0-0-2, III d 0-0-2, IV 0 and femora of palps p 0-0-1; patellae I-IV and patellae of palp 0 ; tibiae I v 1-2-0, p 0-0-1, r 0-0-1 (apical), II v 1-0-3 (apical), p 0-1-1, III v 1-2-2 (apical), p 1-1-0, r 1-10 , IV v 3-2-3 (apical), r 1-0-1 and tibiae of palps p 0-1-0; metatarsi I v 0-0-2 (apical), II v 1-1-2 (apical), p 0-1-0, III v 2-2-8 (apical), p 1-1-1, r 0-1-1, IV v 2-2-1-8 (apical), p $0-1-1$, r $0-1-1$, tarsi I-IV and tarsi of palps 0 .

Palpal organ as in Figures 15A-D, short embolus with short PA, smooth PS keel is not fused with PA, apical part of embolus with short and transparent A keel. Tegulum with distinct TP, projecting prolaterally. Retrolateral face of cymbium without basal field of spiniform setae. Retrolateral face of palpal tibia with indistinct subapical protuberance covered with cluster of numerous spiniform setae (Figure 14A). Two unequal subapical apophyses are present on tibia I (Figure 14B): longer retrolateral tibial apophysis with short, stout spine at apex and shorter prolateral tibial apophysis with single, welldeveloped retrolateral spine at base, approximately two thirds of the length as prolateral tibial apophysis long. Metatarsus I not sigmoidly curved and without basal or median protuberance on retrolateral face. Metatarsus I flexion is between both tibial apophyses.
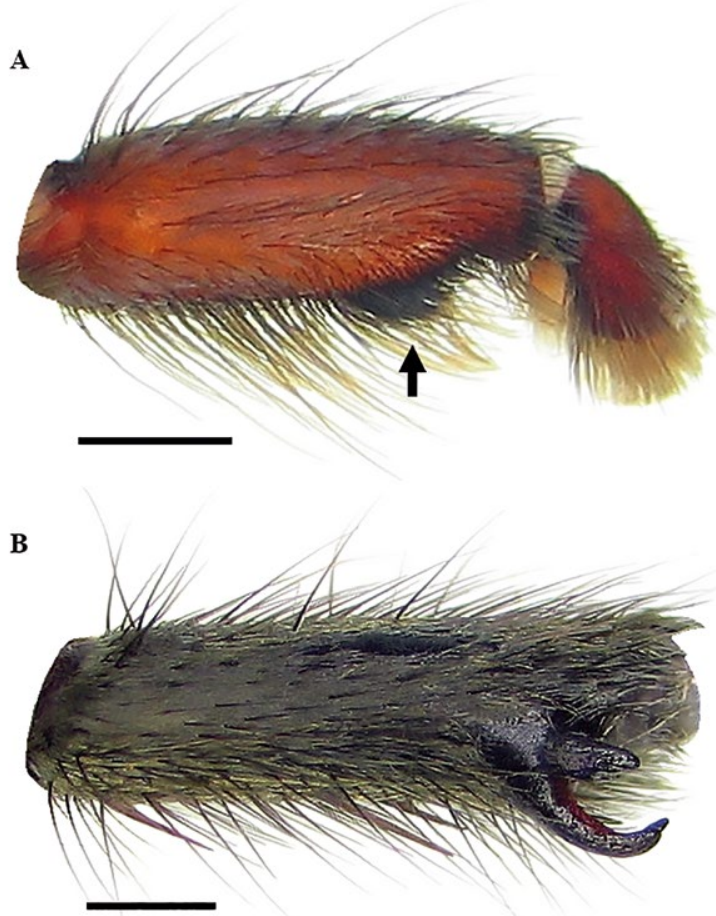

Figure 14. Cyriocosmus foliatus sp. nov., male holotype (MUSM-ENT 0511875) from Peru, Loreto, Iquitos, Umaral. A. Cymbium and tibia of right palp with indistinct retrolateral process, retrolateral view, arrow shows indistinct process covered with numerous spiniform setae. B. Tibia I, prolaterally ventral view. Scale bar $=1 \mathrm{~mm}$. (photos by R. Kaderka)
Abdomen: urticating setae of type III are located in central glossy patch. PLS: length unknown, basal segment 1.64, middle segment 1.17, apical segments are missing, all digitiform. PMS: 0.81 .

Coloration and covering setae: dorsal view (Figures 12, 13A, 13D): carapace uniformly reddish-brown and covered with golden pubescence, without dark caput, coxae, trochantera and chelicerae reddish-brown, and covered with golden pubescence, femora, patellae, tibiae, metatarsi and tarsi black, intermixed with long, pale setae. Patellae I, II and palpal patella with two equal longitudinal stripes without covering setae, patellae III, IV with two unequal diagonal stripes. Abdomen covered with short black setae, intermixed with long, pale setae, except for central reddish-brown glossy patch in the shape of oak leaf. Length of central patch: 3.77, width 2.75. Ventral view (Figures 13B, 13E): labium, sternum, coxae and trochantera reddish-brown, femora, patellae, tibiae and metatarsi black. Abdomen ventrally yellowish
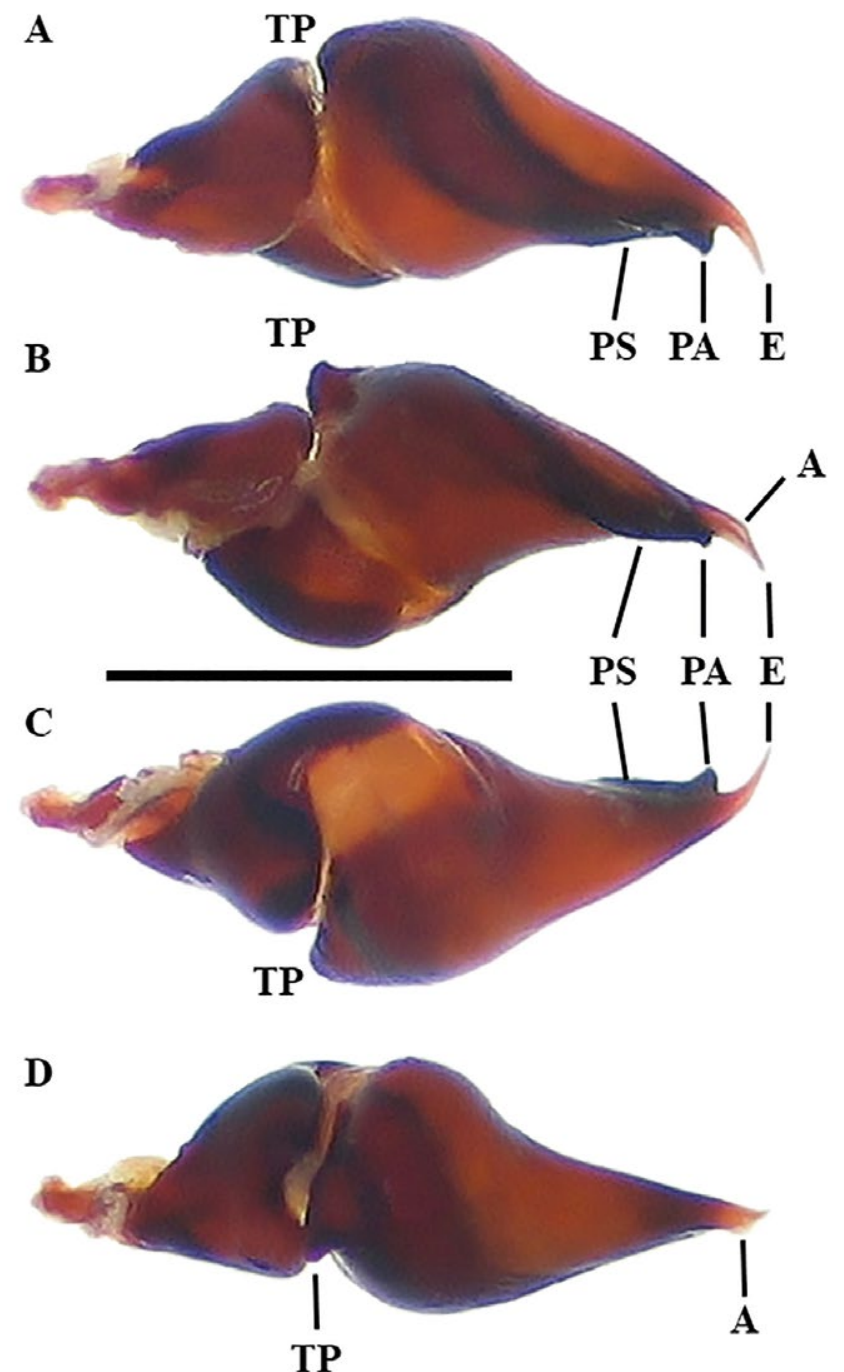

Figure 15. Cyriocosmus foliatus sp. nov., male holotype (MUSM-ENT 0511875) from Peru, Loreto, Iquitos, Umaral. Morphology of right male palpal bulb, prolateral view $(A)$, ventral view $(B)$, retrolateral view (C), dorsal view (D). Scale bar $=1 \mathrm{~mm}$. (photos by R. Kaderka) 


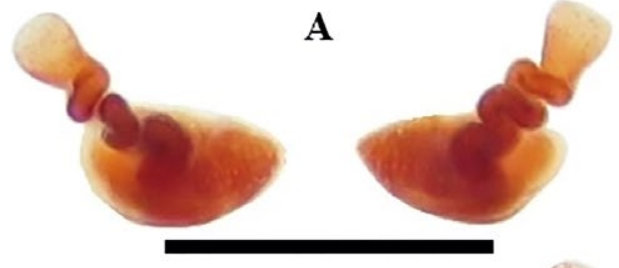

B

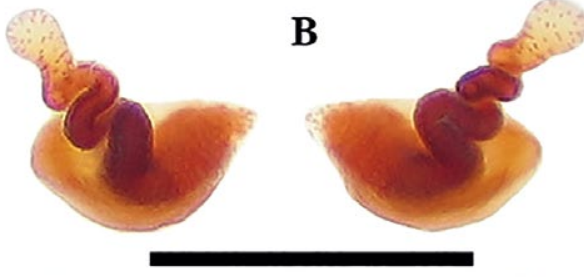

C

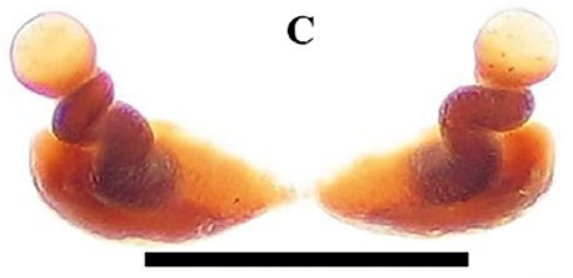

D

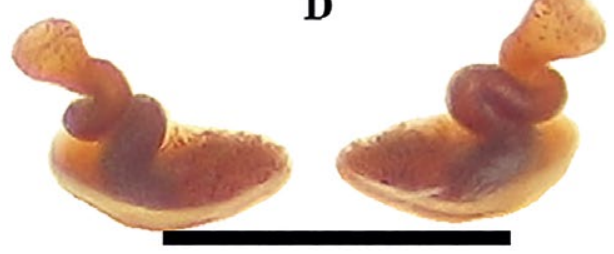

$\mathbf{E}$

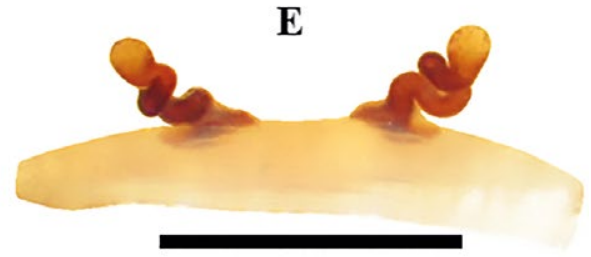

F

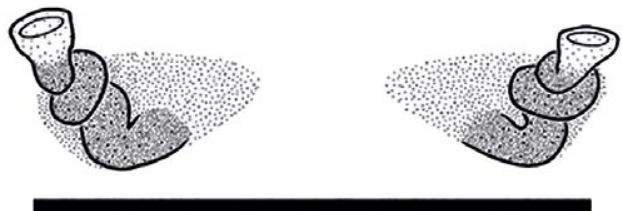

G

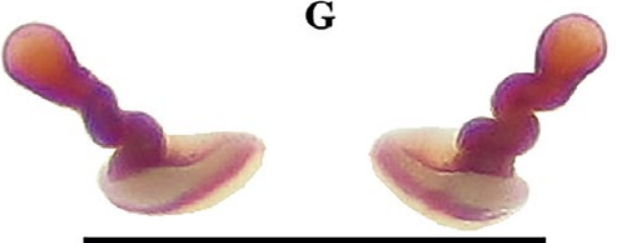

$\mathbf{H}$
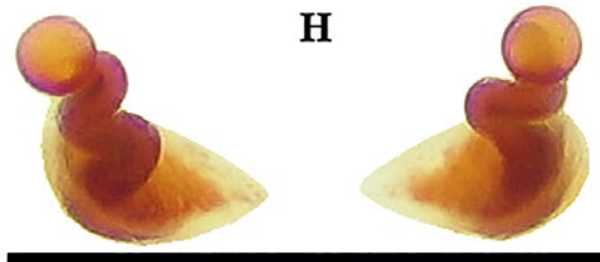

Figure 16. A. Cyriocosmus peruvianus Kaderka 2016, female paratype (NMPC P6A-5726, formerly RKCP 0363) from Peru, Iquitos, Rio Nanay, village of Cuyana. Spermathecae with two separated spiral seminal receptacles, terminated with a caliciform extension, ventral view. B. Cyriocosmus itayensis Kaderka 2016, female paratype (NMPC P6A-5728, formerly RKCP 0367) from Peru, Iquitos, Rio Itaya. Spermathecae with two separated spiral seminal receptacles, terminated with a globular extension, ventral view. C. Cyriocosmus aueri Kaderka 2016, female paratype (NMPC P6A-5730, formerly RKCP 0541) from Peru, Iquitos, the Amazon River, Nuevo Umaral. Spermathecae with two separated spiral seminal receptacles, terminated with a globular extension, ventral view. D. Cyriocosmus sp. 4, female (MUSM-ENT 0511782) from Peru, Loreto, Umaral near lquitos, spermathecae with two spiral seminal receptacles, terminated with a caliciform extension, ventral view. E. Cyriocosmus pribiki Pérez-Miles \& Weinmann 2009, female paratype (SMFD 60238, fragmented female) from Peru, Amazonas, Tingo, Gualap. Spermathecae with two separated spiral seminal receptacles, terminated with a globular extension, including uterus externus, dorsal view. F. Cyriocosmus ritae Pérez-Miles 1998, female (NMPC P6A-5732, formerly RKCP 0348) from Peru, Iquitos, the Amazon River, Las Palmas, spermathecae with two spiral seminal receptacles, terminated with a caliciform extension, ventral view. G. Cyriocosmus giganteus Kaderka 2016, female (MUSM-ENT 0511867) from Peru, Loreto, Estación Biologica Quebrada Blanco near Chino. Spermathecae with two separated spiral seminal receptacles, terminated with a globular extension, ventral view. H. Cyriocosmus sp. 5, female (MUSM-ENT 0506719) from Peru, Madre de Dios, Puerto Maldonado. Spermathecae with two separated spiral seminal receptacles, terminated with a globular extension, ventral view. Scale bar $=1 \mathrm{~mm}$. (photos by R. Kaderka)
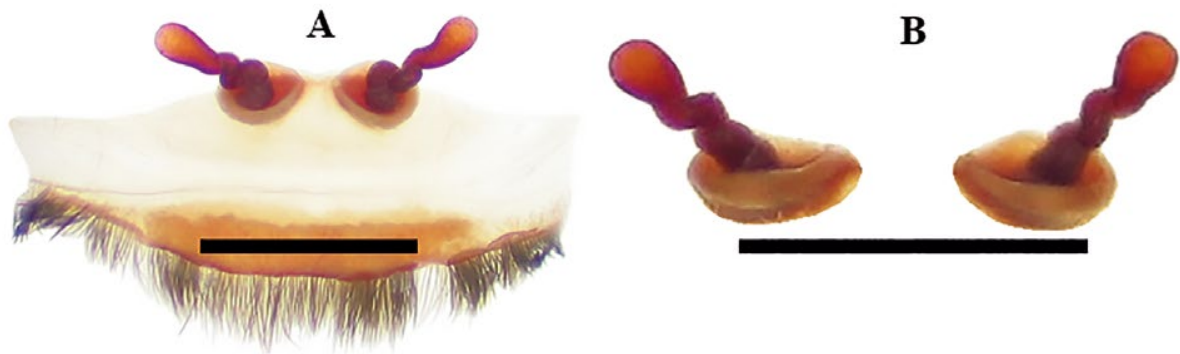

Figure 17. A. Cyriocosmus giganteus Kaderka 2016, female (MUSM-ENT 0511862) from Peru, Loreto, Estación Biologica Quebrada Blanco near Chino. B. Cyriocosmus giganteus Kaderka 2016, female (MUSM-ENT 0511867) from Peru, Loreto, Estación Biologica Quebrada Blanco near Chino. Spermathecae with two separated spiral seminal receptacles, terminated with a globular extension, ventral view. Scale bar $=1 \mathrm{~mm}$. (photos by R. Kaderka) 
brown and without dark longitudinal band (Figure 13E). Spinnerets yelowish brown.

\section{Female: Unknown.}

\section{Key to Cyriocosmus species \\ FEMALES}

(females of Cyriocosmus bertae, C. blenginii, C. paredesi sp. nov. and $C$. foliatus sp. nov. are unknown)

1. Without striped abdominal pattern (Figures 1, 2, 5, 10F, 13D).

- With striped abdominal pattern (Kaderka 2016: figures 12b, 16c, $17 \mathrm{~b}, 22 \mathrm{~b}, 34)$

2. Cephalic area of the same colour as the rest of carapace (Kaderka 2016: figures 3a, 6a, 11a).

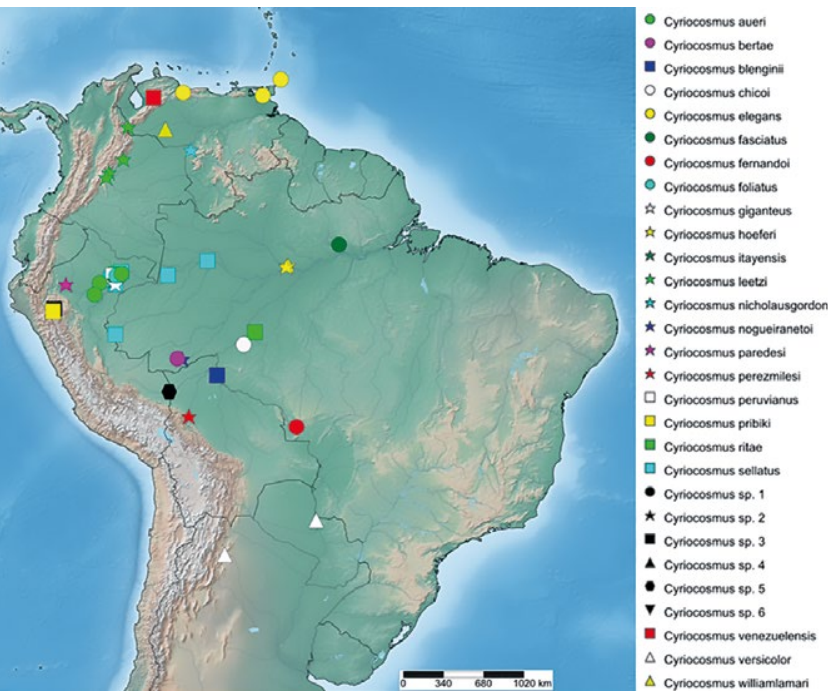

Figure 18. Distribution map of the Neotropic genus Cyriocosmus
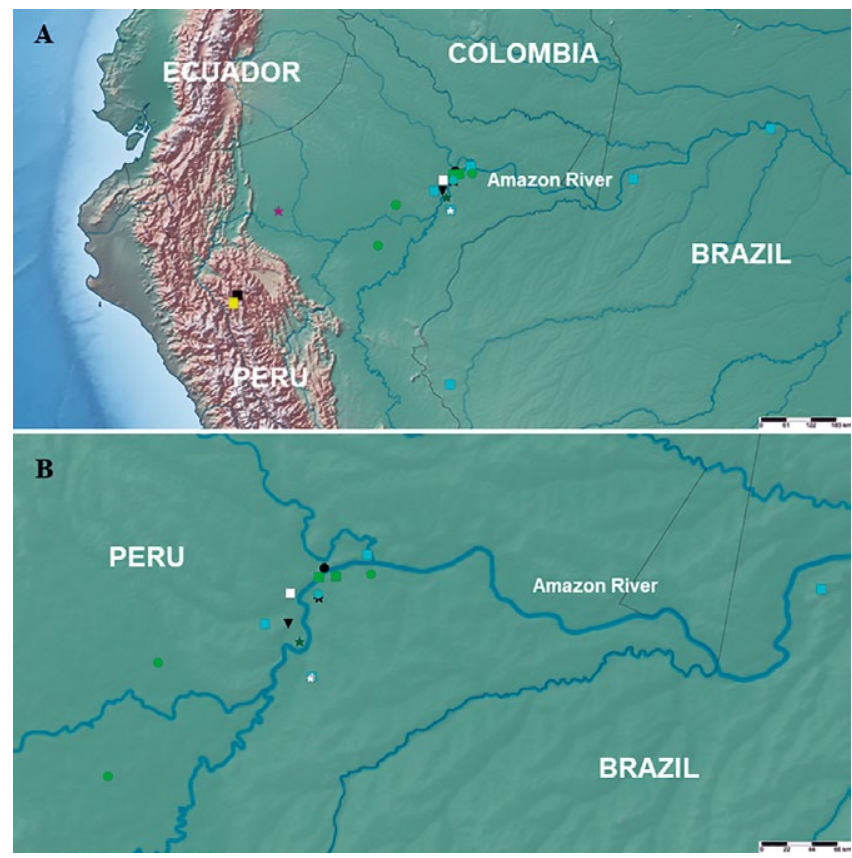

Figure 19. Distribution map of Cyriocosmus species. A. Upper Amazonas. B. Loreto, northern Peru (see Legend in Figure 18).
- Cephalic area black (Fukushima et al. 2005, figure 40). $\quad 7$

3. Seminal receptacles with globular extension (Figures 16B-C, 16E, 16G).

- Seminal receptacles with caliciform extension (Figure 16A), carapace reddish-brown, legs black.

C. peruvianus

4. Basal plates in seminal receptacles absent (Figure 16E).

$$
\text { C. pribiki }
$$

- Basal plates in seminal receptacles present (Figures 16B-C)

5. Basal plates flat (Figure 16B), carapace reddish-brown, legs black. C. itayensis

- Basal plates convex (Figures 16C, 16G), femora black, patellae, tibiae, metatarsi and tarsi brown.

6. Carapace and femora black, patellae, tibiae, metatarsi and tarsi light brown (Kaderka 2016: figure 7)

C. aueri

- Carapace bronze, femora black, patellae, tibiae, metatarsi and tarsi brown (Figure 2). C. giganteus

7. Longitudinal stripes on the dorsal face of the legs present (yellowish), thoracic area black except for two lateral whitish stripes on each side.

C. sellatus

- Longitudinal stripes on the dorsal face of the legs absent, only cephalic area black.

C. versicolor

8. Four lateral stripes on each side of abdomen (Kaderka 2016: figures $14 \mathrm{c}, 16 \mathrm{c}, 19 \mathrm{c}$ ).

- Five lateral stripes on each side of abdomen, cephalic area black (Fukushima et al. 2005, figures 45, 47, 48).

9. Cephalic area of the same colour as the rest of carapace.10

- Cephalic area black.

11

10. Seminal receptacles with flat basal plates, abdomen ventrally without a dark longitudinal band, femora reddish-brown, apically black.

C. perezmilesi

- Seminal receptacles with convex basal plates (Kaderka 2010, figure 6), abdomen ventrally with the longitudinal dark band.

C. venezuelensis

11. Only cephalic area black.

12

- Cephalic area and part of thoracic area black.

12. Abdomen ventrally without a longitudinal dark band (Fukushima et al. 2005 , figures $43,44,46$ )

- Abdomen ventrally with the longitudinal dark band (Kaderka 2016: figure 16e). C. williamlamari

13. Four clear lateral stripes on each side of abdomen, basally joined.

- Three clear lateral stripes on each side of abdomen, basally joined. C. elegans

14. Ratio length/width of urticating setae patch more than 1.4 (Fukushima et al. 2005, figure 44). C. fasciatus

- Ratio length/width of urticating setae patch less than 1.4 (Fukushima et al. 2005, figure 46). C. fernandoi

15. Thoracic area with seven radial black spots (Kaderka 2016: figures 17b, 34).

- Thoracic area black except for whitish lateral stripes on each side (Kaderka 2016: figure 12b).

C. hoeferi

16. Femora with whitish longitudinal stripes on the dorsal face (Kaderka 2016: figure 34).

C. leetzi

- Femora without whitish longitudinal stripes on the dorsal face (Kaderka 2016: figure 17b).

C. nicholausgordon

17. Only cephalic area black, seminal receptacles with sinuous neck (Fukushima et al. 2005, figure 34). C. nogueiranetoi 
- Cephalic and foveal area black (Kaderka 2016: figure 23a).

18. Abdomen ventrally with the longitudinal dark band (Kaderka 2016: figure $23 \mathrm{~d}$ ).

C. ritae

- Abdomen ventrally without a longitudinal dark band (Fukushima et al. 2005, figure 47).

C. bicolor

\section{MALES}

(male of Cyriocosmus williamlamari sp. nov. is unknown)

1. Without striped abdominal pattern (Figures 1, 6D, 10F, 13D)

- With striped abdominal pattern (Kaderka 2016: figures 13c, 17a 22a).

2. PA short (Kaderka 2016: figures 25a-h, 26e-h, 32a-d). 3

- PA long (Kaderka 2016: figures 21f, 26c-d, 32e-f), longitudinal stripes on the dorsal face of the legs present (yellowish), carapace black with two lateral stripes (Kaderka 2016: figure 21a). C. sellatus

3. Coloration of carapace homogenous.

5

- Coloration of carapace non-homogenous.

4

4. Carapace black with two narrow whitish lateral stripes, PS keel smooth, A keel absent (Figure 10,11), zone of retrolateral process of palpal tibia with spiniform setae. C. paredesi sp. nov.

- Cephalic area black, PS keel serrated, A keel present (Fukushima et al. 2005, figures 1,2), zone of retrolateral process of palpal tibia without spiniform setae.

C. versicolor

5. Retrolateral process on male palpal tibia present (Kaderka 2016: figures $2 \mathrm{e}, 5 \mathrm{e})$.

9

- Retrolateral process on male palpal tibia absent (Kaderka 2016: figure 20f).

6. PS keel present (Kaderka 2016: figure 25e-f).

7

- PS keel absent (Kaderka 2016: figure 25g-h). C. giganteus

7. PS keel and PA not fused, A keel present (Figure 15).

$$
\text { C. foliatus sp. nov. }
$$

- PS keel and PA fused, A keel absent.

8

8. PS keel serrated, more quadrangle than half-oval (Fukushima et al. 2005 , figures 3,4 ).

C. bertae

- PS keel smooth, more half-oval than quadrangle (Kaderka 2016: figure $25 \mathrm{e}-\mathrm{f})$, carapace and femora black, patellae, tibiae, metatarsi and tarsi light brown.

C. aueri

9. Retrolateral cymbium with a field of spiniform setae, metatarsus I flexion between both branches.

10

- Retrolateral cymbium without field of spiniform setae, metatarsus I flexion on the apex of retrolateral branch, PS keel smooth, half-oval.

$$
\text { C. pribiki }
$$

10. Carapace reddish-brown, legs black, male palpal bulb as in Kaderka 2016: figures 25a-b, 30a-h. C. peruvianus

- Carapace reddish-brown, legs black, male palpal bulb as in Kaderka 2016: figures $25 \mathrm{c}-\mathrm{d}, 31 \mathrm{e}-\mathrm{h}$. C. itayensis

11. Four lateral abdominal stripes on each side.

12

- Five lateral abdominal stripes on each side, PA long (Fukushima et al. 2005, figures 11, 12, 15-18, 21, 22). 19

12. Cephalic area black.

14

- Cephalic area of the same colour as the rest of carapace, PA short (Kaderka 2016: figure 32g-h).

13

13. Abdomen ventrally with the longitudinal dark band (Kaderka 2010, figure 7).

C. venezuelensis
- Abdomen ventrally without a longitudinal dark band (Kaderka 2007, figure 5), reddish-brown femora, apically black.

C. perezmilesi

14. Only cephalic area black.

15

- Cephalic area and a part of thoracic area black, PA short (Kaderka 2016: figures 26e-h, 32a-d).

15. PA short (Fukushima et al. 2005, figures 7-10).

16

- PA long (Fukushima et al. 2005, figures 13, 14 ).

C. fernandoi

16. Three clear lateral stripes on abdomen, basally joined. C. elegans

- Four clear lateral stripes on abdomen, basally joined.

C. fasciatus

17. Thoracic area with seven radial black spots (Kaderka 2016: figure 17a).

- Thoracic area black except for whitish lateral stripes on each side of carapace (Kaderka 2016: figure 12a).

C. hoeferi

18. Femora with whitish longitudinal stripes on the dorsal face, retrolateral process on palpal tibia is present (Kaderka 2016: figure 18e).

C. leetzi

- Femora without whitish longitudinal stripes on the dorsal face (Kaderka 2016: figure 17a), retrolateral process on palpal tibia is absent (Kaderka 2016: figure 18c).

C. nicholausgordoni

19. Cephalic area black.

20

- Cephalic area of the same colour as the rest of carapace.

$$
\text { C. blenginii }
$$

20. Cephalic and foveal area black.

21

- Only cephalic area black, oval central abdominal patch with anterior T-shaped lobe (Fukushima et al. 2005, figure 45)

C. nogueiranetoi

21. Abdomen ventrally with the longitudinal dark band (Fukushima et al. 2005, figure 48), metatarsus I with median protuberance (Kaderka 2016: figure 24b), tibia I incrassate (Kaderka 2016: figure $24 b)$.

C. ritae

- Abdomen ventrally without a longitudinal dark band.

C. bicolor

\section{Literature cited}

Ausserer A. 1875. Zweiter Beitrag zur Kenntniss der ArachnidenFamilie der Territelariae Thorell (Mygalidae Autor). Verhandlungen der Kaiserlich-Königlichen ZoologischBotanischen Gesellschaft in Wien 25:125-206.

Bertani R. 2000. Male palpal bulbs and homologous features in Theraphosinae (Araneae: Theraphosidae). The Journal of Arachnology 28:29-42.

Bertani R. 2001. Revision, cladistic analysis, and zoogeography of Vitalius, Nhandu, and Proshapalopus; with notes on other theraphosine genera (Araneae, Theraphosidae). Arquivos de Zoología, São Paulo 36 (3):265-356.

Cooke J.A.L., V.D. Roth \& F.H. Miller. 1972. The urticating hairs of theraphosid spiders. American Museum Novitates 2498:1-43.

Fischel W. 1927. Über Südamerikanische Aviculariiden. Zoologischer Anzeiger, Leipzig 74:59-74.

Foelix R. F. 2011. Biology of spiders. Third Edition. Oxford University Press, New York. 411pp.

Fukushima C.S., R. Bertani \& P.I. Da Silva Jr. 2005. Revision of Cyriocosmus Simon, 1903, with notes on the genus Hapalopus Ausserer, 1875 (Araneae: Theraphosidae). Zootaxa 846:1-31. 
Gabriel R. 2017. The revised taxonomical status of Cyclosternum bicolor (Schiapelli \& Gerschman, 1945) (Araneae: Theraphosidae). Journal of the British Tarantula Society 32 (1):10-12.

Kaderka R. 2007. Cyriocosmus perezmilesi sp. n. from Bolivia (Araneae: Theraphosidae: Theraphosinae). Revista Ibérica de Aracnología 14:63-68.

Kaderka R. 2010. Cyriocosmus venezuelensis sp. n. from Venezuela (Araneae: Theraphosidae: Theraphosinae). Revista Ibérica de Aracnología 18:87-96.

Kaderka R. 2016. The Neotropical genus Cyriocosmus Simon, 1903 and new species from Peru, Brazil and Venezuela (Araneae: Theraphosidae: Theraphosinae). Journal of Natural History 50 (7):1-73. https://doi.org/10.10 $80 / 00222933.2015 .1076082$

Mello-Leitão C.F. 1930. Aranhas do Cuminá. Archivos do Museu Nacional do Rio de Janeiro 32:51-75.

Mello-Leitão C.F. 1939. Araignées américaines du Musée d’histoire naturelle de Bâle. Revue Suisse de Zoologie 46:43-93.

Pérez-Miles F., S.M. Lucas, P.I. da Silva Jr. \& R. Bertani. 1996. Systematic revision and cladistic analysis of Theraphosinae (Araneae: Theraphosidae). Mygalomorph, Publication of American Tarantula Society 1 (3):33-68.

Pérez-Miles F. 1998. Revision and phylogenetic analysis of the neotropical genus Cyriocosmus Simon, 1903 (Araneae, Theraphosidae). Bulletin of the British arachnological Society 11 (3):95-103.

Pérez-Miles F. \& D. Weinmann. 2009. Two new species of Cyriocosmus Simon, 1903 from Peru and the highest record for the genus (Araneae: Theraphosidae: Theraphosinae). Revista Ibérica de Aracnología 17:29-35.
Raven R. 1985. The spider infraorder Mygalomorphae (Araneae): cladistics and systematics. Bulletin of American Museum of Natural History 182:1-180.

Roewer C.F. 1942. Katalog der Araneae, Bremen 1:1-1040.

Schiapelli R.D. \& B.S. Gerschman de Pikelin. 1973. El género Cyriocosmus Simon 1901 (Araneae, Theraphosidae). Physis, Seccion C, 32:61-70.

Shorthouse D.P. 2010. SimpleMappr, an online tool to produce publication-quality point maps. <https://www.simplemappr.net>. Accessed May 28, 2019.

Simon E. 1889. Voyage de M. E. Simon au Venezuela (Décembre 1887-Avril 1888), Arachnids. Annales de la Société Entomologique de France 9 (6):169-220.

Simon E. 1897. Liste des Arachnides recueillis aux îles du Cap Vert, dans la République Argentine et le Paraguay et descriptions d'espèces nouvelles. Bolletino dei Musei di Zoologia e Anatomia comparata. Torino 12:1-256.

Simon E. 1903. Histoire naturelle de araignées, Roret, Paris 2 (4):669-1080.

Thorell T. 1869. On European spiders. Part I. Review of the European genera of spiders, preceded by some observations on zoological nomenclature. Nova Acta Regiae Societatis Scientiarum Upsaliensis (3) 7:1-108.

Vol F. 1999. Description d'une nouvelle espéce de Cyriocosmus Simon, 1903 (Araneae, Theraphosidae), Cyriocosmus leetzi sp. n. de Colombie. Arachnides 43:2-10

\begin{abstract}
Acknowledgement
I would like to express my gratitude to the following persons who helped me with this paper. To Diana Silva Dávila from Museo de Historia Natural, Lima for her assistance during my visit to the MUSM spider collection and for comments on an earlier version of this manuscript, to Eckhard W. Heymann from Deutsches Primaten Zentrum in Göttingen, Germany for allowing me a stay in Estación Biológica Quebrada Blanco in Loreto, Peru, to Hubert Höfer from Staatliches Museum für Naturkunde Karlsruhe, Germany, to Christine Rollard from Muséum National d'Histoire Naturelle, Paris, to Peter Jäger and Julia Altmann from Senckenberg Museum, Frankfurt am Main, Germany for access to the specimens lodged in their collections, to Hans-Werner Auer from Germany, Jorge Portilla from Peru and Rick C. West from Canada who provided me with the material for study, photographs and valuable information about the distribution of Cyriocosmus species, to Rick C. West and another anonymous reviewer for their valuable comments on the manuscript and finally to Oscar Magdiel Quispe Colca from Arequipa, Peru for his correction of Spanish abstract. The field work in Peru was carried out under collection permit No. 154-2016-SERFOR/DGGSPFFS.
\end{abstract}

Competing interests:

The author have declared that no competing interests exist.

Funding

No specific funding has been provided for this research.

Aspectos éticos / legales:

Collecting permit No. 154-2016-SERFOR/DGGSPFFS 